\title{
Offshoring and the Role of Trade Agreements
}

\section{Citation}

Antràs, Pol, and Robert W. Staiger. 2008. Offshoring and the role of trade agreements. Nber Working Paper No. 14285.

\section{Published Version}

http://www.nber.org/papers/w14285

\section{Permanent link}

http://nrs.harvard.edu/urn-3:HUL.InstRepos:3374525

\section{Terms of Use}

This article was downloaded from Harvard University's DASH repository, and is made available under the terms and conditions applicable to Open Access Policy Articles, as set forth at http:// nrs.harvard.edu/urn-3:HUL.InstRepos:dash.current.terms-of-use\#OAP

\section{Share Your Story}

The Harvard community has made this article openly available.

Please share how this access benefits you. Submit a story.

Accessibility 
NBER WORKING PAPER SERIES

OFFSHORING AND THE ROLE OF TRADE AGREEMENTS

Pol Antràs

Robert W. Staiger

Working Paper 14285

http://www.nber.org/papers/w14285

\author{
NATIONAL BUREAU OF ECONOMIC RESEARCH \\ 1050 Massachusetts Avenue \\ Cambridge, MA 02138 \\ August 2008
}

We thank Kyle Bagwell, Meredith Crowley, Elhanan Helpman, Alan Sykes and seminar participants at Northwestern University, Stanford University, and the NBER ITI Winter Meeting for helpful comments and discussions. Staiger gratefully acknowledges financial support from the NSF (SES-0518802). Eduardo Morales provided superb research assistance. The views expressed herein are those of the author(s) and do not necessarily reflect the views of the National Bureau of Economic Research.

(C) 2008 by Pol Antràs and Robert W. Staiger. All rights reserved. Short sections of text, not to exceed two paragraphs, may be quoted without explicit permission provided that full credit, including (C notice, is given to the source. 
Offshoring and the Role of Trade Agreements

Pol Antràs and Robert W. Staiger

NBER Working Paper No. 14285

August 2008

JEL No. D02,F02,F13,F5

\begin{abstract}
$\underline{\text { ABSTRACT }}$
The rise of offshoring of intermediate inputs raises important questions for commercial policy. Do the distinguishing features of offshoring introduce novel reasons for trade policy intervention? Does offshoring create new problems of global policy cooperation whose solutions require international agreements with novel features? Can trade agreements that are designed to address problems that arise when trade predominantly takes the form of the exchange of final goods be expected to perform in a world where offshoring is prevalent? In this paper we provide answers to these questions, and thereby initiate the study of trade agreements in the presence of offshoring. We do so by deriving the Nash and internationally efficient trade policy choices of governments in an environment in which some trade flows involve the exchange of customized inputs, contracts governing these transactions are incomplete, and the matching between final-good producers and input suppliers may involve search frictions. By characterizing the differences between Nash and internationally efficient policies in this environment, and by comparing these differences to those that would arise in the absence of offshoring of customized inputs, we seek to understand the implications of offshoring for the role of trade agreements. Our findings indicate that the rise of offshoring is likely to complicate the task of trade agreements, because in the presence of offshoring, (i) the mechanism by which countries can shift the costs of intervention on to their trading partners is more complicated and extends to a wider set of policies than is the case when offshoring is not present, and (ii) because the underlying problem that a trade agreement must address in the presence of offshoring varies with the political preferences of member governments. As a consequence, the increasing prevalence of offshoring is likely to make it increasingly difficult for governments to rely on simple and general rules -- such as reciprocity and non-discrimination -to help them solve their trade-related problems.
\end{abstract}

\author{
Pol Antràs \\ Department of Economics \\ Harvard University \\ 1805 Cambridge Street \\ Littauer Center 319 \\ Cambridge, MA 02138 \\ and NBER \\ pantras@fas.harvard.edu \\ Robert W. Staiger \\ Department of Economics \\ Stanford University \\ 579 Serra Mall \\ Stanford, CA 94305-6072 \\ and NBER \\ rstaiger@stanford.edu
}




\section{Introduction}

International trade in intermediate inputs is a prominent feature of the world economy. Using OECD input-output tables, Ramanarayanan (2006) concludes that in the late 1990s imports of intermediate goods comprised between forty and sixty percent of total merchandise imports for a large number of OECD countries. Similarly, a thorough examination of highly disaggregated trade data led Yeats (2001) to conclude that intermediate input trade accounted for roughly thirty percent of world trade in manufacturing goods in 1995. Furthermore, several authors have noted that the share of intermediate inputs in world trade appears to have increased significantly in recent years. ${ }^{1}$

Recent developments in international trade theory have attempted to bridge the apparent gap between the characteristics of international trade in the data and the standard representation of these trade flows in terms of final goods in neoclassical trade theory. One branch of this new literature has focused on incorporating input trade in otherwise standard models with perfectly competitive markets and frictionless contracting. ${ }^{2}$ Another branch of the literature has stressed that modelling "offshoring" as simply an increase in the fragmentation of production across countries misses important aspects of the characteristics of intermediate input trade. ${ }^{3}$ First, intermediate inputs tend to be much more customized to their intended buyers than final goods, and hence, input trade embodies a disproportionate amount of relationship-specific investments. Second, because contracts involving international transactions are especially hard to enforce, the cross-border exchange of specialized intermediate inputs cannot generally be governed by the same contractual safeguards that usually accompany similar exchanges occurring within borders. A third distinguishing feature of offshoring is that it is often associated with the costly search for suitable foreign suppliers that can provide the required inputs. The recent empirical studies of Feenstra and Hanson (2005), Yeaple (2006), Levchenko (2007), Nunn (2007), and Nunn and Trefler (2008) substantiate the empirical relevance of these non-standard features of offshoring.

The rise of offshoring raises important questions for commercial policy. Do the distinguishing features of offshoring introduce novel reasons for trade policy intervention? Does offshoring create new problems of global policy cooperation whose solutions require international agreements with novel features? Can trade agreements that are designed to address problems that arise when trade predominantly takes the form of the exchange of final goods be expected to perform in a world where offshoring is prevalent?

In this paper we provide answers to these questions, and thereby initiate the study of trade agreements in the presence of offshoring. We do so by deriving the Nash and internationally ef-

\footnotetext{
${ }^{1}$ See, for instance, Feenstra and Hanson (1996b), Feenstra (1998), Campa and Goldberg (1997), Hummels, Ishii and Yi (2001) and Borga and Zeile (2004).

${ }^{2}$ See for instance the work of Feenstra and Hanson (1996a), Jones (2000), Deardorff (2001), Antràs, Garicano and Rossi-Hansberg (2006), or Grossman and Rossi-Hansberg (2008). Antràs and Rossi-Hansberg (2008) review this literature.

${ }^{3}$ Theoretical developments include the work of McLaren (2000), Grossman and Helpman (2002, 2005), Antràs (2003, 2005), and Antràs and Helpman (2004). See Helpman (2006) and Antràs and Rossi-Hansberg (2008) for surveys of this literature.
} 
ficient trade policy choices of governments in an environment in which some trade flows involve the exchange of customized inputs, contracts governing these transactions are incomplete, and the matching between final-good producers and input suppliers may involve search frictions. By characterizing the differences between Nash and internationally efficient policies in this environment, and by comparing these differences to those that would arise in the absence of offshoring of customized inputs, we seek to understand the implications of offshoring for the role of trade agreements.

We adopt the simplest setting that can capture the main features of offshoring that we wish to study, and then later show that our main points are robust to a variety of generalizations. We consider two "small" countries, Home and Foreign, who face a fixed world price for a single homogeneous final good. Production of the final good requires a customized input; all final-good producers are located in Home; and all input suppliers are located in Foreign. Contracts between suppliers and producers are incomplete, and so the terms of exchange between input suppliers and final-good producers are determined by bargaining ex post (after investment in input supply has already been determined). Finally, we abstract initially from political economy concerns, and take real aggregate income as our measure of national and world welfare. In this setting, an international hold-up problem naturally arises under free trade, leading to an inefficiently low volume of input trade.

From this starting point, we turn to an investigation of the role of trade policies. We assume that each country can apply taxes/subsidies to trade in the input and/or the final good. We first reconsider the case for free trade in this environment. As might be expected, the distortions associated with international hold up create an activist role for policy intervention from the perspective of world welfare. Intuitively, the combination of relationship-specific investments and incomplete contracts results in an international hold-up problem that leads to an inefficiently low volume of input trade across countries under free trade, as we have pointed out above. It is therefore natural that trade policies which encourage input trade volume can serve as a substitute for more standard contractual safeguards available in domestic transactions and can thereby help bring countries closer to the efficiency frontier. Importantly, though, the mechanism by which trade policies affect input trade volumes in this environment is by altering the conditions of ex-post bargaining between foreign suppliers and domestic producers, and is therefore distinct from the standard manner that final-goods trade volumes respond to trade policy intervention (through changes in domestic demand and/or competing domestic supply and their implications for market-clearing conditions). Nevertheless, we show that an appropriate choice of input trade subsidies, combined with free trade in final goods, can fully resolve the international hold-up problem and allow countries to attain the first-best.

We next ask whether the Nash equilibrium policy choices of governments coincide with the internationally efficient policies. We find that they do not, and we identify two dimensions of international inefficiency that arise under Nash policies: an inefficiently low input trade volume; and an inefficiently low price of the final good in the Home market. Intuitively, trade policy serves a dual role in this environment. On the one hand, as indicated above, subsidies to the exchange 
of intermediate inputs can serve as a substitute for more standard contractual safeguards available in domestic transactions and can thus increase the volume of input trade toward its efficient level. On the other hand, input trade taxes can be used to redistribute surplus across countries, thereby shifting some of the cost of intervention on to trading partners. For instance, although an export tax may reduce the incentive of Foreign suppliers to invest, in their ex-post bargaining these suppliers will be able to pass part of the cost of the tax on to final-good producers in Home. Moreover, we show that the Home government will also distort trade in the final good away from its freetrade level in order to reduce the domestic final-good price and further shift bargaining surplus from Foreign input suppliers to Home final-good producers in this fashion. There is hence a basic tension that each government faces in its unilateral trade policy choices between correcting the holdup problem and capturing surplus from/shifting costs onto its trading partner, and this tension prevents governments from making internationally efficient policy choices in the Nash equilibrium.

In the absence of offshoring of customized inputs, we show that only the first of the inefficiencies identified above (that associated with input trade policies) is present in the Nash equilibrium, and that the second inefficiency (that associated with Home's final-good tariff) does not arise. Together with the findings above this leads to our first broad conclusion: the rise in offshoring is likely to complicate the task of trade agreements, because in the presence of offshoring the mechanism by which countries can shift the costs of intervention on to their trading partners is more complicated, and extends to a wider set of policies than is the case when offshoring is not present. ${ }^{4}$ More broadly we argue that when international trade involves the offshoring of specialized components, an effective trade agreement must extend its focus beyond the traditional "market access" concerns of establishing and maintaining conditions of competition to cover as well the conditions of bargaining. ${ }^{5}$

We next turn to a particularly relevant extension of our model, and introduce the possibility that governments are motivated in part by political economy/redistributive concerns. We show that the introduction of political economy motives into our model can eliminate unrealistic policy predictions (e.g., convert import subsidies to import taxes and export taxes to export subsidies), but we confirm that the implications of offshoring for the nature of effective trade agreements as described above is preserved. More specifically, we establish that sufficiently politically motivated governments will adopt import tariffs and export subsidies in the Nash equilibrium, but we show that it is still the case that an efficient trade agreement must secure the adoption of input-trade policies that expand the volume of input trade and secure the adoption of final-good trade policies

\footnotetext{
${ }^{4}$ More specifically, we compare the role of a trade agreement in our model of offshoring to that which would arise if there were trade in intermediate inputs but these inputs were not customized. In the latter situation we say that offshoring "is not present" in order to draw a distinction between that situation and the characteristics of offshoring that we emphasize in this paper.

${ }^{5}$ This feature also distinguishes our framework from the work of Brander and Spencer (1985), who emphasize the potential profit-shifting effects of export subsidies in the presence of imperfect competition. Although our model also features a profit-shifting motive for trade policy, the novel conclusions we reach regarding the task of a trade agreement could not be derived in their framework, due to the market-clearing nature of prices in their model. Bagwell and Staiger (2002, Ch. 9) formalize this point by showing that the assumption of Cournot oligopoly alone does not change the basic terms-of-trade/market-access problem for a trade agreement to solve.
} 
in Home that raise the final-good price in Home's market.

We also use our political-economy extension to consider the link between the role of trade agreements in the presence of offshoring and the role of trade agreements according to the (politically augmented) terms-of-trade theory. Here we follow Bagwell and Staiger (1999) with one important distinction: in our model of offshoring, we show that the terms-of-trade impacts of trade policies can be sorted into "good" and "bad" components. With this distinction, we borrow terminology from Bagwell and Staiger and define politically optimal policies as those policies that would hypothetically be chosen by governments unilaterally if they took account of the good terms-of-trade impacts of their intervention while placing zero value on the bad. We then ask whether politically optimal tariffs are efficient, and thereby explore whether the Nash inefficiencies described above can be given a modified terms-of-trade interpretation, according to which the fundamental problem faced by governments in designing their trade agreement is to find ways to eliminate the "bad" terms-oftrade manipulation while maintaining/encouraging the "good."

We show that the Nash inefficiency associated with input trade policies can indeed be given a modified terms-of-trade interpretation along the lines described above. But we show that the Nash inefficiency associated with the Home final-good trade policy can only be given such an interpretation if governments lack political economy motives: when political economy motives are present, there exists a distinct problem for a trade agreement to solve with respect to final-good trade policy that cannot be given even a modified terms-of-trade interpretation.

Again, in the absence of offshoring of customized inputs we show that a (standard) terms-oftrade interpretation applies, and together with the findings above this leads to our second broad conclusion: if political economy motives are taken to be widespread and varied, then the rise in offshoring is likely to complicate the task of trade agreements, because the underlying problem that a trade agreement must address varies with the political preferences of member governments. As a consequence, under the view that governments operate in the presence of important political economy forces, the increasing prevalence of offshoring is likely to make it increasingly difficult for governments to rely on simple and general rules - such as reciprocity and non-discrimination - to help them solve their trade-related problems.

Our paper is related to several literatures. First, as emphasized above, by exploring the role of trade agreements in a model with intermediate input trade and in an environment with relationshipspecific investments and incomplete contracting, we complement and extend an established literature on international trade agreements (see Bagwell and Staiger, 2002, Ch. 2, for a review of this literature). In suggesting a novel rationale for trade agreements, our paper also complements the recent paper by Ossa (2008). Second, by considering endogenous trade policy choices in this environment, we complement and extend a recent literature that has begun to study the impacts of (exogenous) tariffs on international hold-up problems. Ornelas and Turner (2008a) develop a model in which import tariffs on intermediate inputs are shown to aggravate the hold-up problem in international vertical relationships, with the implication that trade liberalization may lead to a larger increase in trade flows than in standard models. Ornelas and Turner do not however study 
optimal trade policies or the possibility of trade agreements in their framework. ${ }^{6,7}$ McLaren (1997) studies the desirability of announcing a future trade liberalization in a model where producers incur sunk costs to service foreign markets, but his framework emphasizes commitment problems from which we completely abstract. ${ }^{8}$

Finally, there is a large literature proposing a variety of mechanism-design resolutions to the hold-up inefficiencies caused by incomplete contracts. These resolutions however generally rely on the ability of parties to commit not to renegotiate an initial contract and also on the existence of a third party that can enforce off-the-equilibrium-path penalties. ${ }^{9}$ We view our international context as one in which these alternative resolutions of the hold-up problem are naturally more problematic, and thus trade taxes and subsidies may be particularly useful in resolving these inefficiencies. For this same reason, we find it natural to simplify our model in a way that avoids completely any source of domestic hold-up inefficiencies. ${ }^{10}$

The rest of the paper is organized as follows. In section 2, we develop a Benchmark Model that introduces the international hold-up problem and illustrates the valuable role of active second-best trade policies. In section 3, we consider Nash equilibrium policy choices and show that they leave room for a welfare-enhancing international trade agreement. In section 4, we develop an extension with politically motivated governments and relate our theory of trade agreements to the termsof-trade theory. In section 5, we consider a variety of extensions of the model. We offer some concluding remarks in section 6 .

\section{The Benchmark Model}

We begin this section by describing a benchmark two-small-country trade model in which final-good producers in the home country import inputs from suppliers in the foreign country. We refer to this model as the Benchmark Model. While simple and special along a number of dimensions, the Benchmark Model is meant to highlight the essential features of the basic international hold-up problem which arises under free trade. After presenting the setup and characterizing the free-trade equilibrium, we derive the (second-best) trade policies that maximize world welfare.

\footnotetext{
${ }^{6}$ The recent and independent paper of Ornelas and Turner (2008b) does begin to explore the welfare implications of tariffs in this kind of environment, but their focus is very different from ours and they do not consider the possible role of trade agreements.

${ }^{7}$ Similarly, Antràs and Helpman (2004) and Diez (2008) study the effect of trade frictions on the choice of organizational form of firms contemplating offshoring, but they also treat trade frictions as exogenous.

${ }^{8}$ Yarbrough and Yarbrough (1992) also emphasize commitment problems associated with trade relationships that involve substantial relationship- (or market-) specific investments, but they focus on how these issues affect the choice between unilateral liberalization, bilateral agreements and multilateral agreements.

${ }^{9}$ Bolton and Dewatripont (2005, Chapter 12) offer an excellent overview of the insights and limitations of this literature.

${ }^{10}$ In related work, Rosenkranz and Schmitz (2007) show that, in a closed economy setup, a government can use taxation to alleviate the hold-up problem between domestic buyers and sellers.
} 


\subsection{Setup}

We consider a world of two small countries, Home $(H)$ and Foreign $(F)$, and a large rest-of-world whose only role in the model is to fix the price at which a final good 1 is available to $H$ and $F$ on world markets (the direction of trade in good 1 is not specified and is immaterial). Consumer preferences are identical in $H$ and $F$ and given by

$$
U^{j}=c_{0}^{j}+u\left(c_{1}^{j}\right)
$$

where $c_{i}^{j}$ is consumption of good $i \in\{0,1\}$ in country $j \in\{H, F\}$, and where $u^{\prime}>0$ and $u^{\prime \prime}<0$. Good 0, which we take to be the numeraire, is assumed to be costlessly traded and available in sufficient quantities that it is always consumed in positive amounts in both $H$ and $F$. Good 1 is produced with a customized intermediate input $x$ according to the production function $y(x)$, with $y^{\prime}(x)>0$ and $y^{\prime \prime}(x)<0 .{ }^{11}$ By choice of units for measuring the quantity of good 1 , we set its (fixed) price on world markets equal to 1 . For now we assume that trade in good 1 is free, so that its price is equal to 1 everywhere in the world.

We suppose that the home country $H$ is inhabited by a unit measure of producers of the final good 1 , while the foreign country $F$ is inhabited by a unit measure of suppliers of the intermediate input $x$. Hence, to produce the final good 1, producers in $H$ must import inputs from suppliers in $F$. Suppliers in $F$ tailor their inputs specifically to the needs of a final-good producer in $H$ and, for simplicity, these inputs are assumed to be useless to alternative final-good producers. We assume that the marginal cost of input production in $F$ is constant and, through choice of the units in which inputs are measured, we normalize it to 1 . For now, we also assume that trade in $x$ is free.

We next turn to focus on the nature of the bilateral relationship between a final-good producer in $H$ and an input supplier in $F$, which comprises the essence of the model. We adopt a setting of incomplete contracts between final-good producers and input suppliers. In our Benchmark Model, contractual incompleteness can be rationalized in the following simple way. Following Grossman and Helpman (2002) and Antràs (2003), we assume that, when investing in the supply of $x$, the supplier can choose between manufacturing a high-quality or a low-quality input, and the latter can be produced at lower cost but is useless to final-good producers. The quantity of $x$ is observable to everyone and therefore verifiable by third-parties, but we assume that the quality of $x$ is only observable to the supplier and producer in the particular bilateral relationship, and so qualitycontingent contracts are not available. Although parties could still sign a contract specifying a price and a quantity, if they did so, the supplier would always have an incentive to produce the low quality input (at lower cost) and still receive the same contractually stipulated price.

Hence, in this environment, no (enforceable) contracts are signed between suppliers and producers prior to the initial supplier investment decisions. And without an initial contract, the price at which each supplier in $F$ sells its inputs to a producer in $H$ is then decided ex-post (through bargaining) once quality has been chosen. We follow the bulk of the literature in assuming that the

\footnotetext{
${ }^{11}$ In order to ensure that the second-order conditions are met, we will later impose additional assumptions on $y(x)$.
} 
bargained price is determined through symmetric Nash bargaining. Because parties have symmetric information at the bargaining stage, ex-post efficiency ensures that low-quality production will never be chosen by an input supplier in equilibrium, and so only high-quality inputs are produced: as a result, the input-quality dimension of the model can be kept in the background henceforth.

We now describe the structure of the bilateral producer-supplier relationship in detail. We assume that all agents have an ex-ante zero outside option. The sequence of events is as follows:

stage 1. The unit measure of producers in $H$ and suppliers in $F$ are randomly matched, producing a unit measure of matches. Each agent decides whether to stay with his match or exit the market. In the former case, the producer provides the supplier with a list of customized input specifications. In the latter case, each agent obtains his ex-ante outside option (equal to zero).

stage 2. Each supplier decides on the amount $x$ of customized input to be produced (at marginal cost of 1).

stage 3. Each producer-supplier pair bargains over the price of the intermediate input (we assume symmetric Nash bargaining).

stage 4. Each producer in $H$ imports $x$ from its partner-supplier and produces the final good with the acquired $x$, and payments agreed in stage 3 are settled.

This 4-stage game generates the simple hold-up problem that forms the heart of our analysis. A number of features of this setup are worth noting at this point.

First, we rule out the use of ex-ante (stage-1) lump-sum transfers between producers and suppliers. The possibility of these transfers is particularly hard to defend in the international context that we study, where such transfers and the obligations associated with them might be difficult to enforce. In section 5, however, we will show that our main results are robust to allowing for these transfers. Second, we assume a frictionless matching process in stage 1 to keep our Benchmark Model simple: in section 5 we introduce search frictions. Third, the role of the specificity of input $x$ is to pin down the outside options of the producer and the supplier should their stage3 bargaining break down. In our Benchmark Model we take an extreme view of the degree of specificity, so that the breakup of a bargaining pair in stage 3 would result in a zero outside option for both producer and supplier. We relax this assumption in section 5, where we introduce a secondary market for inputs. Fourth, we assume symmetric Nash bargaining in stage 3 . This helps to keep the number of parameters to a minimum in our Benchmark Model and allows us to focus on the main points. However, we also relax this assumption in section 5, where we consider general bargaining power.

Finally, we note that production efficiency requires that the customized input is produced at a level $x^{E}$ which satisfies

$$
y^{\prime}\left(x^{E}\right)=1
$$


and thereby equates the marginal revenue generated from an additional unit of the input (recall that the price of the final good is fixed by world markets and equal to 1 under free trade) with the marginal cost of producing an additional unit of the input (which is constant and normalized to 1).

\subsection{Free Trade Equilibrium}

We now characterize the subgame perfect equilibrium of the 4-stage game described above. The characterization follows very simply from a few key observations. We consider a representative producer in $H$ and supplier in $F$ that are matched in stage 1.

First, if the producer uses the supplier's input to produce the final good in stage 4, its revenue is given by $y(x)$. Second, as observed in the previous section, the outside options of both the producer and the supplier in their stage-3 Nash bargain are 0 , and hence the quasi-rents over which the producer and supplier bargain in stage 3 (recall that the cost of producing $x$ is sunk at this point) are $y(x)$. Therefore, in the symmetric Nash bargain of stage 3 , the final-good producer in $H$ and the input supplier in $F$ both obtain a payoff of $\frac{1}{2} y(x)$.

Next, rolling back to stage 2 , observe that the input supplier chooses $x$ to maximize $\frac{1}{2} y(x)-x$, so the optimal quantity $\hat{x}$ of input satisfies

$$
y^{\prime}(\hat{x})=2 .
$$

Given the concavity of $y(x)$, it is clear from a comparison of (3) with (2) that $\hat{x}<x^{E}$. This is the under-investment associated with the hold-up problem, and it reflects the fact that the producer and supplier bargain over the price of the input after the supplier has already sunk investment in input supply.

Finally, consider stage 1. If the producer hands the supplier a list of customized input specifications, the producer anticipates obtaining a payoff equal to

$$
\pi^{H}=\frac{1}{2} y(\hat{x})
$$

which exceeds the payoff he would obtain by not providing the specifications (recall that the ex-ante outside option of producers is equal to 0). Similarly, by agreeing to form a partnership with the home producer, the supplier anticipates obtaining a payoff of

$$
\pi^{F}=\frac{1}{2} y(\hat{x})-\hat{x}
$$

which also exceeds his ex-ante outside option. ${ }^{12}$ In sum, no separations will occur at stage 1 . Note also that the sum of payoffs of the two parties is equal to $y(\hat{x})-\hat{x}$, which is strictly less than the sum of payoffs that would obtain when investment is chosen at the efficient level $x^{E}$ defined by (2).

Now consider the measure of social welfare in each country implied by our Benchmark Model. With our assumption of quasilinear preferences, this measure is given by consumer surplus plus

\footnotetext{
${ }^{12}$ Given the concavity of $y(x)$, we have $\frac{1}{2} y(\hat{x})-\hat{x} \geq \frac{1}{2} \hat{x} y^{\prime}(\hat{x})-\hat{x}=0$.
} 
profits plus trade tax revenue (the latter being zero under free trade). ${ }^{13}$ Using (1), we have that country $j$ 's demand for good 1 is given by $D_{1}\left(p_{1}^{j}\right) \equiv u^{\prime-1}\left(p_{1}^{j}\right)$, with consumer surplus then defined as $C S^{j}\left(p_{1}^{j}\right) \equiv \int_{p_{1}^{j}}^{\bar{p}} D_{1}(p) d p$ where $\bar{p}$ is the "choke" price for country $j$ 's demand of good 1 . World aggregate welfare may then be represented by

$$
W^{W}=W^{H}+W^{F}=C S^{H}(1)+C S^{F}(1)+\pi^{H}+\pi^{F}=C S^{H}(1)+C S^{F}(1)+y(\hat{x})-\hat{x},
$$

which is strictly lower than world welfare in the presence of production efficiency because $y(\hat{x})-\hat{x}<$ $y\left(x^{E}\right)-x^{E}$. We summarize this discussion with:

Proposition 1 In the Benchmark Model, a hold-up problem exists under free trade, leading to an inefficiently low volume of input trade $\left(\hat{x}<x^{E}\right)$.

Proposition 1 records the existence of a basic international hold-up problem that arises in the presence of free trade. At this point, there are a variety of mechanism-design resolutions to the hold-up inefficiencies caused by incomplete contracts that we might consider. However, we view our international context as one in which these mechanism-design resolutions are naturally more problematic because they generally rely on the ability of parties to commit not to renegotiate an initial contract and also on the existence of a third party that can enforce off-the-equilibrium-path penalties. In this light, trade taxes and subsidies may be particularly useful as an alternative route to resolving these inefficiencies. We therefore next turn to consider trade intervention as a possible means of alleviating the hold-up problem.

\subsection{Second-Best Trade Policy}

In this section, we explore the possible beneficial role of trade policy in this distorted economy. To this end, we let $\tau_{x}^{H}$ denote the trade tax imposed by $H$ on imports of the input $x$ (positive if an import tariff, negative if an import subsidy) defined in specific terms, and we let $\tau_{x}^{F}$ be the analogous trade tax imposed by $F$ (positive if an export tax, negative if an export subsidy). Furthermore, we let $\tau_{1}^{H}$ denote the trade tax imposed by $H$ on the home country's trade in the final good 1 (positive if an import tariff or export subsidy, negative if an import subsidy or export tax) also defined in specific terms. Observe that the price of the final good 1 in $H$ is now given by $p_{1}^{H}=1+\tau_{1}^{H}$, whereas the price of the input $x$ continues to be determined by Nash bargaining between producers and suppliers (though trade taxes may affect this negotiated price). ${ }^{14}$

How does the introduction of these trade taxes affect the equilibrium characterized in the previous section? To explore this question, we first consider the case of second-best trade policies,

\footnotetext{
${ }^{13}$ Strictly speaking, social welfare should also include a term related to income earned by other factors of production (say labor) in the economy. Nevertheless, it is straightforward to close the model in a way that makes this term independent of policies in sector 1 (see, for instance, Grossman and Helpman, 1994). Henceforth, we simply ignore this term.

${ }^{14}$ We could also allow for a final-good trade $\operatorname{tax} \tau_{1}^{F}$ in the foreign country, but it is intuitively clear (and is easily shown) that there will be no incentive to use such an instrument, since such trade taxes could only alter the local price of good 1 in $F$ (owing to $F$ 's small size on world markets) and that price has no impact on the hold-up problem between $F$ 's input suppliers and $H$ 's final good producers.
} 
that is, the set of policies that maximize aggregate world welfare (subject to the contractual frictions in producer-supplier relationships). More specifically, we introduce the following stage 0 which occurs prior to stage 1 of the 4-stage game described in section 2.1:

stage 0. A social planner selects a home-country trade tax $\tau_{1}^{H}$ on the final good 1, a home-country import tax $\tau_{x}^{H}$ on home imports of the input $x$, and a foreign-country export tax $\tau_{x}^{F}$ on foreign exports of the input $x$.

After the social planner has selected these import tariffs/subsidies in stage 0 , the sequence of events is as outlined in section 2.1 (with trade taxes collected at the time of importation and production/sales in stage 4).

Consider now how these trade policy choices in stage 0 affect the equilibrium outcome of the game. In their stage-3 bargaining, if the producer and supplier reach an agreement they stand to obtain a joint payoff of (recalling again that the cost of producing $x$ is sunk at that point)

$$
\left(1+\tau_{1}^{H}\right) y(x)-\left(\tau_{x}^{H}+\tau_{x}^{F}\right) x .
$$

A positive import tariff or export subsidy on the final good $\left(\tau_{1}^{H}>0\right)$ raises the joint surplus of the producer and supplier because it raises the price at which the final good is sold in $H$. Conversely, a positive import tariff $\left(\tau_{x}^{H}>0\right)$ or export tax $\left(\tau_{x}^{F}>0\right)$ on inputs reduces the joint surplus of the producer and supplier because it transfers part of the surplus to governments.

If the producer and the supplier do not reach an agreement, each is again left with a zero outside option. Hence, both parties obtain a payoff equal to $\frac{1}{2}\left(\left(1+\tau_{1}^{H}\right) y(x)-\left(\tau_{x}^{H}+\tau_{x}^{F}\right) x\right)$ in the Nash bargain of stage 3 , and the input supplier's choice of $x$ in stage 2 must then satisfy ${ }^{15}$

$$
\frac{1}{2}\left(1+\tau_{1}^{H}\right) y^{\prime}(\hat{x})=1+\frac{1}{2}\left(\tau_{x}^{H}+\tau_{x}^{F}\right) .
$$

It is clear from (4) that $\hat{x}$ is increasing in $\tau_{1}^{H}$ and decreasing in $\tau_{x}^{H}$ and $\tau_{x}^{F}$. Intuitively, incomplete contracting leads to rent-sharing between the producer and supplier, and the latter's incentives to invest tend to be higher whenever the surplus from investment is higher, that is when $\tau_{1}^{H}$ is higher and when $\tau_{x}^{H}$ or $\tau_{x}^{F}$ are lower. We will see in later sections that the positive dependence of $\hat{x}$ on $\tau_{1}^{H}$ and negative dependence of $\hat{x}$ on $\tau_{x}^{H}$ and $\tau_{x}^{F}$ hold for a variety of specifications of the game played between the producer and supplier.

At stage 1, the final-good producer in $H$ anticipates a payoff equal to

$$
\pi^{H}=\frac{1}{2}\left(\left(1+\tau_{1}^{H}\right) y(\hat{x})-\left(\tau_{x}^{H}+\tau_{x}^{F}\right) \hat{x}\right)
$$

\footnotetext{
${ }^{15}$ Implicit in our discussion is the assumption that $\frac{1}{2}\left(\left(1+\tau_{1}^{H}\right) y(x)-\left(\tau_{x}^{H}+\tau_{x}^{F}\right) x\right)>0$, so that the Nash bargain payoff beats each party's outside option. It is straightforward to show that this is true in our Benchmark Model for the relevant values of home and foreign policies. When we introduce a secondary market in section 5.1 , this is no longer self-evident, and at that point we consider the associated non-negativity constraints (which are formally treated in Appendix A.2).
} 
while the supplier in $F$ expects a payoff equal to

$$
\pi^{F}=\frac{1}{2}\left(\left(1+\tau_{1}^{H}\right) y(\hat{x})-\left(\tau_{x}^{H}+\tau_{x}^{F}\right) \hat{x}\right)-\hat{x}
$$

where $\hat{x}$ is implicitly defined by (4). As a result, welfare in $H$, inclusive of tax revenue, is given by

$$
W^{H}=C S^{H}\left(1+\tau_{1}^{H}\right)+\pi^{H}+\tau_{1}^{H}\left[D_{1}\left(1+\tau_{1}^{H}\right)-y(\hat{x})\right]+\tau_{x}^{H} \hat{x}
$$

while welfare in $F$ is

$$
W^{F}=C S^{F}(1)+\pi^{F}+\tau_{x}^{F} \hat{x} .
$$

We now seek to characterize the set of trade policy choices that maximize world welfare. Formally, we are seeking the triplet $\left(\tau_{1}^{H E}, \tau_{x}^{H E}, \tau_{x}^{F E}\right)$ that maximizes (see (5) and (6)):

$$
W^{W}=W^{H}+W^{F}=C S^{H}\left(1+\tau_{1}^{H}\right)+C S^{F}(1)+\left(1+\tau_{1}^{H}\right) y(\hat{x})-\hat{x}+\tau_{1}^{H}\left[D_{1}\left(1+\tau_{1}^{H}\right)-y(\hat{x})\right],
$$

subject to $\hat{x}$ being given by (4). ${ }^{16}$ Notice that for a given value of the sum $\tau_{x}^{H}+\tau_{x}^{F}$, the individual values of $\tau_{x}^{H}$ and $\tau_{x}^{F}$ have no effect on world welfare. This implies that the second-best policies will only pin down an aggregate input trade tax $\tau_{x} \equiv \tau_{x}^{H}+\tau_{x}^{F}$. The efficient policies $\tau_{1}^{H E}$ and $\tau_{x}^{E}$ are then determined by the following first-order conditions of the problem above: ${ }^{17}$

$$
\begin{aligned}
\frac{\partial W^{W}}{\partial \tau_{1}^{H}} & =\tau_{1}^{H} \frac{\partial D_{1}}{\partial p_{1}^{H}}+\left[y^{\prime}(\hat{x})-1\right] \frac{\partial \hat{x}}{\partial \tau_{1}^{H}}=0, \text { and } \\
\frac{\partial W^{W}}{\partial \tau_{x}} & =\left[y^{\prime}(\hat{x})-1\right] \frac{\partial \hat{x}}{\partial \tau_{x}}=0 .
\end{aligned}
$$

The first-order conditions in (7) are instructive. Recalling from (4) that $\partial \hat{x} / \partial \tau_{1}^{H}>0$, it is clear from (7) that the optimal choice of $\tau_{1}^{H}$ is strictly positive, provided that $\left[y^{\prime}(\hat{x})-1\right]>0$ which by (2) implies that $\hat{x}<x^{E}$ : this suggests that an import tariff or export subsidy on trade in the final good 1 could raise welfare in the world, by increasing $\hat{x}$ toward $x^{E}$ and thereby helping to ameliorate the hold-up problem at the cost of lost consumer surplus. However, recalling from (4) that $\partial \hat{x} / \partial \tau_{x}<0$, it is clear from (7) that the optimal choice of $\tau_{x}$ must ensure that $\left[y^{\prime}(\hat{x})-1\right]=0$, thereby achieving productive efficiency: there is no associated loss in consumer surplus when the tariff on imported inputs $\tau_{x}$ is used to increase $\hat{x}$, and the optimal choice of $\tau_{x}$ therefore solves completely the hold-up problem and achieves productive efficiency. This in turn leaves no reason for government intervention with regard to trade in the final good 1. Hence, the optimal choice of $\tau_{1}^{H}$ is $\tau_{1}^{H E}=0$. On the other hand, the second-best policies do call for intervention with regards to input trade. In particular, from equation (4) it follows that the optimal trade tax is an input subsidy in an amount equal to $\tau_{x}^{E} \equiv \tau_{x}^{H E}+\tau_{x}^{F E}=-1$. We may thus state:

\footnotetext{
${ }^{16}$ It is the presence of this constraint that leads us to refer to $\left(\tau_{1}^{H E}, \tau_{x}^{H E}, \tau_{x}^{F E}\right)$ as second-best trade policy choices, although we shall show that these policy choices lead to an attainment of the first-best welfare level.

${ }^{17}$ It is easily checked that second-order conditions are satisfied (see Appendix A.1).
} 
Proposition 2 In the Benchmark Model, the second-best trade policy choices maintain free trade in the final good and subsidize importation of the input so as to solve the hold-up problem and achieve an efficient volume of input trade $\left(\hat{x}=x^{E}\right)$.

The intuition for Proposition 2 is simple. The hold-up problem between producers in $H$ and suppliers in $F$ results in a level of imported inputs which is inefficiently low. The market failure is an international one in nature, and thus it is natural that trade taxes or subsidies can serve a useful role in alleviating the inefficiency. Furthermore, although trade intervention in the final good could be used to raise the home-country price of the final good and increase the volume of imported inputs (through rent-sharing), this would come at a cost of reduced home-country consumer surplus. A subsidy to imported inputs does not reduce consumer surplus, but it nevertheless succeeds in increasing the volume of imported inputs by increasing the surplus over which the parties negotiate in the ex-post (stage-3) bargain. As a consequence, a subsidy to imported inputs targets just the distorted margin, and in analogy with the targeting principle (Bhagwati and Ramaswami, 1963, Johnson, 1965) is hence the optimal method of addressing the problem.

We have thus identified a novel role for trade policy intervention, namely, as a means of addressing the international hold-up problem that arises when international trade requires relationshipspecific investments between domestic producers and their foreign suppliers. A natural question is whether the unilateral trade policy choices of both the home and foreign governments will lead to overall trade interventions that concord with the efficiency conditions outlined in Proposition 2. We tackle this issue in the next section.

\section{Nash Trade Policy and the Role of Trade Agreements}

In this section we characterize the Nash policies of the home and foreign governments and evaluate the potential role of trade agreements in our Benchmark Model. In order to build intuition, we first consider the unilaterally optimal trade policy choices of the home government when the foreign government follows a policy of free trade, and only later consider the possibility of foreign trade policy intervention.

\subsection{Unilateral Home Policy}

To characterize the unilaterally optimal trade policy choices of the home government when the foreign government follows a policy of free trade, we derive the subgame perfect equilibrium of the Benchmark Model for the case in which stage 0 is as follows: ${ }^{18}$

\footnotetext{
${ }^{18}$ Implied by this timing of tariff choices is the assumption that governments can make tariff commitments to the private sector. If the governments did not have this ability, then as is well known a separate commitment role for trade agreements might arise (see Bagwell and Staiger, 2002, Chapter 2, for a review of this literature). The particular commitment problems that governments face when trade requires relationship-specific investments are emphasized by Yarbrough and Yarbrough (1992) as providing a reason for trade agreements to exist, and by McLaren (1997) as creating the possibility of perverse negotiating outcomes. Our assumed timing permits us to abstract from the possible commitment role of trade agreements throughout this paper, so that we may focus on other issues.
} 
stage 0 . The home government $H$ selects a trade tax $\tau_{1}^{H}$ on the final good 1, and a trade $\operatorname{tax} \tau_{x}^{H}$ on the imported input $x$; the foreign government $F$ remains passive, i.e., $\tau_{x}^{F} \equiv 0$.

Following the same steps as in the last section, and with $\tau_{x}^{F}$ set to zero at stage 0 , we have that the final-good producer in $H$ now obtains a stage-2 payoff equal to:

$$
\pi^{H}=\frac{1}{2}\left(\left(1+\tau_{1}^{H}\right) y(\hat{x})-\tau_{x}^{H} x\right)
$$

where $\hat{x}$ is now implicitly defined by

$$
\frac{1}{2}\left(1+\tau_{1}^{H}\right) y^{\prime}(\hat{x})=1+\frac{1}{2} \tau_{x}^{H} .
$$

With these expressions in hand, home welfare can be written as the sum of home consumer surplus, profits and tax revenue, or

$$
W^{H}=C S\left(1+\tau_{1}^{H}\right)+\frac{1}{2}\left(\left(1+\tau_{1}^{H}\right) y(\hat{x})-\tau_{x}^{H} \hat{x}\right)+\tau_{1}^{H}\left[D_{1}\left(1+\tau_{1}^{H}\right)-y(\hat{x})\right]+\tau_{x}^{H} \hat{x} .
$$

The optimal choice of $\tau_{1}^{H}$ and $\tau_{x}^{H}$, which we denote by $\hat{\tau}_{1}^{H}$ and $\hat{\tau}_{x}^{H}$, must maximize home welfare $W^{H}$, and will hence satisfy the first-order conditions

$$
\begin{aligned}
\frac{\partial W^{H}}{\partial \tau_{1}^{H}} & =0=\tau_{1}^{H} \frac{\partial D_{1}}{\partial p_{1}^{H}}-\frac{1}{2} y(\hat{x})+\left[\frac{1}{2}\left(1-\tau_{1}^{H}\right) y^{\prime}(\hat{x})+\frac{1}{2} \tau_{x}^{H}\right] \frac{\partial \hat{x}}{\partial \tau_{1}^{H}}, \text { and } \\
\frac{\partial W^{H}}{\partial \tau_{x}^{H}} & =0=\frac{1}{2} \hat{x}+\left[\frac{1}{2}\left(1-\tau_{1}^{H}\right) y^{\prime}(\hat{x})+\frac{1}{2} \tau_{x}^{H}\right] \frac{\partial \hat{x}}{\partial \tau_{x}^{H}}
\end{aligned}
$$

where recall that $\hat{x}$ is given by equation (9). ${ }^{19}$ Applying the implicit function theorem (twice) to (9) delivers

$$
\frac{\partial \hat{x} / \partial \tau_{1}^{H}}{\partial \hat{x} / \partial \tau_{x}^{H}}=-y^{\prime}(\hat{x}),
$$

which can be used to manipulate the above first-order conditions to obtain:

$$
\begin{aligned}
& \hat{\tau}_{1}^{H}=-\frac{\frac{1}{2} \hat{x}\left[\frac{y(\hat{x})}{\hat{x}}-y^{\prime}(\hat{x})\right]}{\left|\partial D_{1} / \partial p_{1}^{H}\right|}, \text { and } \\
& \hat{\tau}_{x}^{H}=-\left(1-\hat{\tau}_{1}^{H}\right) y^{\prime}(\hat{x})-\frac{\hat{x}}{\partial \hat{x} / \partial \tau_{x}^{H}} .
\end{aligned}
$$

The expressions in (10) reflect an interesting logic. Part of the goal of the home government in intervening with $\tau_{1}^{H}$ and/or $\tau_{x}^{H}$, as in the case of second-best policies, is to raise $\hat{x}$ towards its efficient level $x^{E}$. Nevertheless, the home government does not maximize world welfare and hence there is an offsetting leakage of surplus to the foreign supplier that must be taken into account

\footnotetext{
${ }^{19}$ The second-order conditions for this problem do not reduce to simple expressions, as was the case with secondbest policies. In Appendix A.1, we discuss these second-order conditions and show that they are satisfied for a simple parameterized example.
} 
by the home government in setting its optimal unilateral policies. This leads to two observations: first, it is not optimal for the home government to deliver the chosen $\hat{x}$ using only $\tau_{x}^{H}$, and the setting of $\tau_{1}^{H} \neq 0$ reflects a new and independent source of international inefficiency associated with the unilateral policy choices of the home country; and second, it is not optimal for the home government to raise $\hat{x}$ all the way to its efficient level $x^{E}$.

The first observation can be understood as follows. The home government must concern itself with two tasks as it considers its policy choices. First, it must face foreign suppliers with the appropriate marginal incentives for investment in the supply of $x$ so as to achieve the desired investment level $\hat{x}$. Second, the home government must also concern itself with extracting inframarginal surplus from foreign suppliers through the use of trade policy instruments.

With its two tariff instruments $\tau_{1}^{H}$ and $\tau_{x}^{H}$, the home government can extract infra-marginal foreign surplus with adjustments in $\tau_{1}^{H}$ and $\tau_{x}^{H}$ that hold $\hat{x}$ fixed according to $(9)$, so that $d \tau_{x}^{H}\left(\tau_{1}^{H}\right) / d \tau_{1}^{H}=$ $-\frac{\partial \hat{x} / \partial \tau_{1}^{H}}{\partial \hat{x} / \partial \tau_{x}^{H}}=y^{\prime}(\hat{x})$, and can extract foreign surplus in this fashion at the rate

$$
\left.\frac{d W^{F}\left(\tau_{1}^{H}, \tau_{x}^{H}, \hat{x}\right)}{d \tau_{1}^{H}}\right|_{d \hat{x}=0}=\frac{1}{2} \hat{x}\left[\frac{y(\hat{x})}{\hat{x}}-y^{\prime}(\hat{x})\right]
$$

Evidently, with the concavity of $y(x)$ implying $\left[\frac{y(\hat{x})}{\hat{x}}-y^{\prime}(\hat{x})\right]>0$, it follows from (11) that for any given level of $\hat{x}$, additional surplus can be extracted from the foreign country by reducing $\tau_{1}^{H}$ and accompanying this with a reduction in $\tau_{x}^{H}$ which preserves the level of $\hat{x}$. Intuitively, while we have seen that a positive final-good tariff $\tau_{1}^{H}$ could be used to induce greater investment from foreign suppliers, from the perspective of foreign surplus extraction it is an inferior method for doing so relative to a subsidy to imported inputs $\tau_{x}^{H}$, because $\tau_{1}^{H}$ must work through the final-good production function $y(x)$ - which is concave - and this creates more infra-marginal surplus for foreign suppliers relative to $\tau_{x}^{H}$, which works directly (and linearly) through import volume $x$.

What, then, prevents the home country from lowering $\tau_{1}^{H}$ and $\tau_{x}^{H}$ in this fashion indefinitely, until all of the surplus has been extracted from foreign suppliers? The impact on home-country welfare of these tariff changes is given by

$$
\left.\frac{d W^{H}\left(\tau_{1}^{H}, \tau_{x}^{H}, \hat{x}\right)}{d \tau_{1}^{H}}\right|_{d \hat{x}=0}=\tau_{1}^{H} \frac{\partial D_{1}^{H}}{\partial p_{1}^{H}}-\frac{1}{2} \hat{x}\left[\frac{y(\hat{x})}{\hat{x}}-y^{\prime}(\hat{x})\right]
$$

As (12) makes clear, what eventually stops this process of foreign surplus extraction is the growing home-country final-good demand distortions that are associated with $\tau_{1}^{H}<0$.

It is for these reasons that $(10)$ implies $\hat{\tau}_{1}^{H}<0$ : in words, it is unilaterally optimal for the home government to utilize trade policy to distort downward the price of the final good 1 in the home market (through either an import subsidy or an export tax on the final good) as a means of extracting bargaining surplus from foreign suppliers. Finally, recalling that $W^{W}=W^{H}+W^{F}$, 
note that (11) and (12) together imply

$$
\left.\frac{d W^{W}}{d \tau_{1}^{H}}\right|_{d \hat{x}=0}=\tau_{1}^{H} \frac{\partial D_{1}^{H}}{\partial p_{1}^{H}},
$$

which is strictly positive for $\tau_{1}^{H}<0$ : in words, setting $\tau_{1}^{H}<0$ is inefficient from the point of view of aggregate world welfare for any level of $\hat{x}$. Hence, our model identifies a new and independent source of international inefficiency when the home country sets its tariffs unilaterally: the attempt to extract bargaining surplus from foreign suppliers by distorting the home market price of the final good.

The second observation above, that it is not optimal for the home country to raise $\hat{x}$ all the way to its efficient level $x^{E}$, can be confirmed by considering the expression for $\hat{\tau}_{x}^{H}$ in (10). This expression is of indeterminate sign, indicating that $\hat{\tau}_{x}^{H}$ can now be either negative (an import subsidy on inputs of $x$ ) or positive (an import tariff on inputs of $x$ ): this reflects the tension that arises for the home-country government between correcting the hold-up problem and capturing surplus from the foreign input supplier, a tension that was absent in the choice of second-best policies in section 2.3. To see more formally that the home government will not raise $\hat{x}$ to the efficient level, substitute (9) into the expression for $\hat{\tau}_{x}^{H}$ in (10) and simplify to obtain

$$
y^{\prime}(\hat{x})=1-\frac{1}{2} \frac{\hat{x}}{\partial \hat{x} / \partial \tau_{x}^{H}}>1
$$

which implies that $\hat{x}<x^{E}$. Hence, at least when the foreign government remains passive, it is unilaterally optimal for the home government to utilize its trade policies in a way that does not fully correct the international hold-up problem.

We can thus conclude that, when only $H$ intervenes, international efficiency is not achieved. Instead, there are now two sources of international inefficiency that arise: an inefficiently low input trade volume that results from the continued existence of the international hold-up problem; and distortions in the final good market that arise as a result of the home-country's attempts to extract bargaining surplus from foreign suppliers. We may thus state:

Proposition 3 In the Benchmark Model, when only $H$ intervenes with trade policy, its unilaterally optimal policy choices lead to (i) an inefficiently low volume of input trade ( $\hat{x}<x^{E}$ ), and (ii) an inefficiently low local price for the final good in $H$ 's market.

Proposition 3 stands in marked contrast to Proposition 2, and reflects a simple point. To the extent that home-country producers share part of the surplus from production with foreign suppliers (as is the case in our Benchmark Model), the unilateral incentives of the home-country government to intervene with trade policy to mitigate the international hold-up problem will be muted by the fact that foreign suppliers enjoy some of the benefits of this intervention. In this environment, the home-country's unilateral intervention must be concerned as well with capturing foreign surplus, and therefore the home country cannot be counted on to solve the international 
hold-up problem on its own. Moreover, the home-country's attempts to extract bargaining surplus from foreign suppliers will spill over into the final good market as well, and introduce additional distortions there.

\subsection{Foreign Intervention and Nash Policy Choices}

We turn next to consider the unilateral incentives of the foreign government to intervene with a trade $\operatorname{tax} \tau_{x}^{F}$ (as before, in a prior stage 0 ). We hence modify stage 0 as follows:

stage $\mathbf{0}$. The home government $H$ selects a trade tax $\tau_{1}^{H}$ on the final good 1 , and a trade tax $\tau_{x}^{H}$ on the imported input $x$; simultaneously, the foreign government $F$ selects a trade $\operatorname{tax} \tau_{x}^{F}$ on the exported input $x .^{20}$

We start by considering $F$ 's incentive to intervene facing a given $H$ policy pair $\left(\tau_{1}^{H}, \tau_{x}^{H}\right)$. In this case, the input supplier in $F$ now has a payoff of

$$
\pi^{F}=\frac{1}{2}\left(1+\tau_{1}^{H}\right) y(\hat{x})-\left(1+\frac{1}{2} \tau_{x}^{H}+\frac{1}{2} \tau_{x}^{F}\right) \hat{x}
$$

with $\hat{x}$ defined by

$$
\frac{1}{2}\left(1+\tau_{1}^{H}\right) y^{\prime}(\hat{x})=1+\frac{1}{2} \tau_{x}^{H}+\frac{1}{2} \tau_{x}^{F}
$$

Foreign welfare is then given by the sum of foreign consumer surplus, profits and tax revenue:

$$
W^{F}=C S^{F}(1)+\frac{1}{2}\left(1+\tau_{1}^{H}\right) y(\hat{x})-\left(1+\frac{1}{2} \tau_{x}^{H}+\frac{1}{2} \tau_{x}^{F}\right) \hat{x}+\tau_{x}^{F} \hat{x} .
$$

The optimal choice of $\tau_{x}^{F}$, which we denote by $\hat{\tau}_{x}^{F}$, hence must satisfy the first-order condition

$$
\left.\frac{\partial W^{F}}{\partial \tau_{x}^{F}}=0=\frac{1}{2} \hat{x}+\left[\frac{1}{2}\left(1+\tau_{1}^{H}\right) y^{\prime}(\hat{x})-1-\frac{1}{2} \tau_{x}^{H}+\frac{1}{2} \tau_{x}^{F}\right)\right] \frac{\partial \hat{x}}{\partial \tau_{x}^{F}} .
$$

Recalling that $\partial \hat{x} / \partial \tau_{x}^{F}<0$, the first-order condition in (15) together with (14) immediately implies that

$$
\tau_{x}^{F}=-\frac{1}{2} \frac{\hat{x}}{\partial \hat{x} / \partial \tau_{x}^{F}}>0
$$

and hence, the foreign country finds it optimal to set an export tax on the intermediate input.

The logic behind this result can be understood as follows. First, why doesn't F's government offer an export subsidy to increase exports of $x$ and help address the hold-up problem? The reason is that the level of $x$ is already chosen by the foreign supplier to maximize foreign profits, and so there is no gain to the foreign country from manipulating this choice with export-sector intervention. And second, foreign suppliers do not bear the full cost of the increase in the marginal cost of production associated with an export tax, because they have less than full bargaining power

\footnotetext{
${ }^{20}$ As in the case of second-best policies, we could allow for foreign taxes on trade in the final good 1 , but these have no effect on the hold-up problem and will thus never be used as a part of an optimal set of policies.
} 
in their negotiations with final-good producers. Hence, the foreign government is able to pass part of the cost of the export tax on to the home country while keeping the entire benefit from it (in the form of tax revenue). As a result, the optimal export tax is positive.

How will the home country respond to the setting of an export tax by $F$ ? In order to derive the Nash policy choices of the home country, we next solve for the final-good $\operatorname{tax} \tau_{1}^{H}$ and the input tax $\tau_{x}^{H}$ that maximize home welfare for a given foreign policy choice $\tau_{x}^{F}$. This pair will thus maximize

$$
W^{H}=C S\left(p_{1}^{H}\right)+\frac{1}{2}\left(\left(1+\tau_{1}^{H}\right) y(\hat{x})-\tau_{x}^{H} \hat{x}-\tau_{x}^{F} \hat{x}\right)+\tau_{1}^{H}\left[D_{1}\left(p_{1}^{H}\right)-y(\hat{x})\right]+\tau_{x}^{H} \hat{x}
$$

subject to $\hat{x}$ being given by (14). Manipulating the first-order conditions and replacing $\tau_{x}^{F}$ with $\hat{\tau}_{x}^{F N} \equiv-(1 / 2) \hat{x} /\left(\partial \hat{x} / \partial \tau_{x}^{F}\right)$ yields the following conditions defining the home Nash pair $\left(\hat{\tau}_{1}^{H N}, \hat{\tau}_{x}^{H N}\right)$ :

$$
\begin{aligned}
& \hat{\tau}_{1}^{H N}=-\frac{\frac{1}{2} \hat{x}\left[\frac{y(\hat{x})}{\hat{x}}-y^{\prime}(\hat{x})\right]}{\left|\partial D_{1} / \partial p_{1}^{H}\right|}, \text { and } \\
& \hat{\tau}_{x}^{H N}=-\left(1-\hat{\tau}_{1}^{H N}\right) y^{\prime}(\hat{x})-\frac{\hat{x}}{\partial \hat{x} / \partial \tau_{x}^{H}}+\hat{\tau}_{x}^{F N} .
\end{aligned}
$$

The first equation implies that $\hat{\tau}_{1}^{H N}$ is again negative, while the second indicates that the sign of $\hat{\tau}_{x}^{H N}$ is indeterminate. This parallels the results we obtain in the case without foreign retaliation as recorded in (10), and the intuition is the same as that outlined above. The only difference is the additional term $\hat{\tau}_{x}^{F N}>0$ in the second equation, which other things equal leads to overall higher input taxes. Combining the above expressions for $\hat{\tau}_{1}^{H N}$ and $\hat{\tau}_{x}^{H N}$ with equations (14) and (16) we further obtain:

$$
y^{\prime}(\hat{x})=1-\frac{\hat{x}}{\partial \hat{x} / \partial \tau_{x}^{H}} .
$$

It is then clear that the Nash equilibrium involves suboptimal trade in intermediate inputs, $\hat{x}<x^{E}$. In sum, we have shown that:

Proposition 4 In the Nash equilibrium of the Benchmark Model, F maintains free trade in the final good and taxes the exports of the input, while $H$ intervenes in both the final-good and input markets, resulting in (i) an inefficiently low volume of input trade $\left(\hat{x}<x^{E}\right)$, and (ii) an inefficiently low local price for the final good in H's market.

\subsection{The Role of a Trade Agreement}

Proposition 4 characterizes the nature of the inefficiencies that arise in the Nash equilibrium of the Benchmark Model. If the Nash policy choices are thought to represent the choices that governments would make in the absence of a trade agreement, then Proposition 4 identifies the source of potential mutual gain from a trade agreement in the presence of offshoring. Evidently, this source has two distinct dimensions: a first dimension is to secure the adoption of input trade policies that address the international holdup problem between $H$ 's producers and F's suppliers, and thereby expand 
input trade volume to the internationally efficient level; a second dimension is to secure the adoption of final-good trade policies in $H$ that do not distort bargaining between $H$ 's producers and $F$ 's suppliers, and thereby raise the local price of the final good in $H$ 's market to the internationally efficient level.

These observations point to an important insight. When trade involves the offshoring of specialized components, the source of potential mutual gain from a trade agreement is different than when trade involves the exchange of non-specialized products such as the final goods traditionally considered in the literature on trade agreements. The key point is that, in the case of offshoring, the terms of trade are determined by bilateral bargains between foreign suppliers and domestic buyers, and this feature gives rise to the two distinct dimensions of potential mutual gain from a trade agreement described above. By contrast, when trade involves non-specialized products, the terms of trade are determined by market clearing conditions, and in these circumstances a trade agreement can offer only one dimension of potential mutual gain: the expansion of trade volume.

More specifically, in the context of final-goods trade where market clearing determines the terms of trade, Bagwell and Staiger (2001) have shown that trade agreements exist - according to the "terms-of-trade theory" - for the sole purpose of expanding trade volume to internationally efficient levels, even when governments have an array of policy instruments that they might potentially distort. In Appendix B, we extend their result to an input-trade setting analogous to the one considered here, assuming however that intermediate inputs are not customized to their intended users, but are rather produced by a competitive fringe of suppliers. In order to open the door for terms-of trade manipulation, we also let the two countries be large enough in input markets to affect world input prices. In the Appendix we establish that, provided the terms at which inputs are traded internationally is determined by a market-clearing condition (as would naturally be the case with homogenous inputs), a trade agreement only offers the first dimension of potential mutual gain mentioned above, that of expanding input trade volume to the internationally efficient level. It is therefore only when the terms of trade are determined by bilateral bargains between foreign suppliers and domestic buyers - as in the case of offshoring of specialized components - that a trade agreement can provide the second dimension of potential mutual gain listed above, namely, securing the adoption of final-good trade policies in $H$ that do not distort bargaining between $H$ 's producers and F's suppliers.

Notice, though, that this last observation carries with it a critical implication. When trade involves the offshoring of specialized components, a trade agreement cannot achieve the international efficiency frontier through traditional "market access" negotiations that would simply seek to establish and maintain appropriate conditions of competition for foreign input suppliers into the domestic market, or more specifically that would seek to establish appropriate restraints on those government policies that can alter the conditions of competition. Rather, the agreement must also cover those government policies that can alter the conditions of bargaining.

To see the distinction, consider the two home tariffs $\tau_{x}^{H}$ and $\tau_{1}^{H}$. When international prices of traded inputs (the terms at which inputs are traded) are determined by international market clear- 
ing conditions, it is immaterial to foreign input suppliers whether the home government facilitates a given equilibrium level of input trade by stimulating demand for imported inputs with a relatively low tariff on imported inputs $\left(\tau_{x}^{H}\right)$ and a relatively low local price for the final good (through a low final-good import tariff or export subsidy $\tau_{1}^{H}$ ), or rather with a relatively high $\tau_{x}^{H}$ and a relatively high local price for the final good (through a high $\tau_{1}^{H}$ ). Either way, with the quantity of home demand for imported inputs pinned down, the market-clearing international price of the inputs will be pinned down as well, and hence foreign exporters of inputs can expect to sell the same volume into the home market at the same price, and hence can expect to receive the same surplus. Therefore, when the terms at which inputs are traded are determined by international market clearing conditions, trade negotiations need only be concerned with establishing and maintaining the level of home market access for foreign input suppliers, not the precise combination of home policies $\tau_{x}^{H}$ and $\tau_{1}^{H}$ that are used to deliver that access. This implies in turn that, provided negotiations over $\tau_{x}^{H}$ are understood to imply a market access commitment (and recalling that $H$ is assumed to be small in world markets for the final good 1), there is no need for negotiations to cover $\tau_{1}^{H}$.

But when the terms at which inputs are traded are determined by bilateral bargaining, as in our model of offshoring, this is no longer the case: as we have shown in (11), different combinations of the two home tariffs $\tau_{x}^{H}$ and $\tau_{1}^{H}$ will imply different levels of surplus for foreign exporters of the input, even when these different combinations lead to the same equilibrium volume of input trade. Hence, it is no longer enough for trade negotiations to be concerned only with establishing and maintaining the level of home market access for foreign input suppliers: the negotiations must also be concerned with the precise combination of home policies $\tau_{x}^{H}$ and $\tau_{1}^{H}$ that are used to deliver that access. In other words, the agreement must also cover the conditions of bargaining, or more specifically those government policies that can alter the conditions of bargaining.

In our Benchmark Model, it is the home tariff on the final good, $\tau_{1}^{H}$, that reflects this new coverage. More generally, there are many policies - including internal/domestic measures - that could potentially alter the conditions of bargaining between foreign suppliers and domestic buyers of specialized components. The main message here is that the increasing prevalence of offshoring is likely to complicate the task of a trade agreement, by requiring that it move away from a narrow focus on market access and toward increasing coverage of a wider array of policy instruments.

We summarize this discussion with: ${ }^{21}$

Proposition 5 In the Benchmark Model, the role of a trade agreement is to: (i) secure the adoption of input trade policies that expand input trade volume to the internationally efficient level; and (ii) secure the adoption of final-good trade policies in $H$ that raise the local price of the final good in $H$ 's market to the internationally efficient level.

Since the second role identified in Proposition 5 only arises when the terms at which inputs are

\footnotetext{
${ }^{21}$ Although we have not concerned ourselves with how the trade agreement will divide the surplus between the two countries, it is worth mentioning that the particular values of $\tau_{x}^{H}$ and $\tau_{x}^{F}$ can always be chosen to ensure that both countries are better off under the agreement than under the status quo with Nash tariffs. This in turn implies that a successful agreement does not require the exchange of lump sum transfers.
} 
traded is determined by bilateral bargaining, we may also state the following:

Corollary 1 When international trade involves the offshoring of specialized components, an effective trade agreement must extend its focus beyond the traditional market access concerns of establishing and maintaining conditions of competition to cover as well the conditions of bargaining.

\section{The Benchmark Model with Political Economy}

We have thus far assumed that each country's government is benevolent and seeks to maximize the aggregate welfare of its residents. Both casual and formal evidence suggest, however, that it is more realistic to formulate a social welfare function that weights asymmetrically the welfare of different groups in society. The political economy literature has stressed the role of special interest groups in generating these biases in policy (Baron, 1994, Grossman and Helpman, 1996).

In this section, we extend the Benchmark Model to allow for government welfare functions that place a higher weight on producer welfare than on consumer welfare. We first observe that the introduction of political economy motives can eliminate unrealistic features of the Benchmark Model's policy predictions (e.g., convert import subsidies to import tariffs), but we confirm that the inefficiencies associated with the Nash equilibrium as described in Proposition 4 and the role of a trade agreement as described in Proposition 5 still apply.

We then consider whether the underlying problem that a trade agreement must address in this setting can be given a terms-of-trade interpretation along the lines of the (politically augmented) terms-of-trade theories that feature prominently in the trade-agreements literature. As can be anticipated from our earlier discussion, the standard terms-of-trade interpretation does not apply to our model, but we show here that a modified terms-of-trade interpretation can be given to the problem that a trade agreement must fix as it relates to the input trade policies $\tau_{x}^{H}$ and $\tau_{x}^{F}$; on the other hand, we show that this modified terms-of-trade interpretation extends to the home final-

good trade policy $\tau_{1}^{H}$ if and only if foreign political economy motives are absent. After establishing these results, we discuss their relevance for understanding the novel role of trade agreements in the presence of offshoring.

For simplicity, except where it might cause confusion we continue to refer to the politically augmented Benchmark Model as simply the Benchmark Model.

\subsection{Introducing Political Economy}

To represent political-economy motives, we implicitly assume that producers are in a better position to solve the "collective action" problem and hence can better coordinate their demands on the government. We also assume that the ownership of productive assets is highly concentrated, so that we can ignore the role of producers as consumers and as receivers of lump-sum tax rebates. In particular, we let:

$$
W^{j}=C S^{j}+\gamma^{j} \pi^{j}+\text { Trade Tax Revenue }{ }^{j}, \quad \text { with } \gamma^{j} \geq 1 \text {, for } j \in\{H, F\},
$$


where $\gamma^{j}$ represents the weight that the government of country $j$ places on the welfare of its producers, with political-economy motives present in country $j$ if and only if $\gamma^{j}>1$. Using (5), (6) and (18), the welfare of the home and foreign governments in the (politically augmented) Benchmark Model can be written as

$$
W^{H}=C S\left(p_{1}^{H}\right)+\gamma^{H}\left(\frac{1}{2}\left(1+\tau_{1}^{H}\right) y(\hat{x})-\frac{1}{2}\left(\tau_{x}^{H}+\tau_{x}^{F}\right) \hat{x}\right)+\tau_{1}^{H}\left[D_{1}\left(p_{1}^{H}\right)-y(\hat{x})\right]+\tau_{x}^{H} \hat{x}
$$

and

$$
W^{F}=C S(1)+\gamma^{F}\left(\frac{1}{2}\left(1+\tau_{1}^{H}\right) y(\hat{x})-\frac{1}{2}\left(\tau_{x}^{H}+\tau_{x}^{F}\right) \hat{x}-\hat{x}\right)+\tau_{x}^{F} \hat{x},
$$

respectively. $^{22}$

The first-order conditions that define the Nash policies $\hat{\tau}_{1}^{H N}, \hat{\tau}_{x}^{H N}$, and $\hat{\tau}_{x}^{F N}$ can be written as:

$$
\begin{aligned}
\frac{\partial W^{H}}{\partial \tau_{1}^{H}}=0 \Rightarrow \tau_{1}^{H} \frac{\partial D_{1}}{\partial p_{1}^{H}}+\left(\frac{\gamma^{H}}{2}-1\right) \hat{x}\left[\frac{y(\hat{x})}{\hat{x}}-y^{\prime}(\hat{x})\right]=0, \\
\frac{\partial W^{H}}{\partial \tau_{x}^{H}}=0 \Rightarrow\left(1-\frac{\gamma^{H}}{2}\right) \hat{x}+\left[\gamma^{H}+\tau_{x}^{H}-\tau_{1}^{H} y^{\prime}(\hat{x})\right] \frac{\partial \hat{x}}{\partial \tau_{x}^{H}}=0, \text { and } \\
\frac{\partial W^{F}}{\partial \tau_{x}^{F}}=0 \Rightarrow\left(1-\frac{\gamma^{F}}{2}\right) \hat{x}+\tau_{x}^{F} \frac{\partial \hat{x}}{\partial \tau_{x}^{F}}=0 .
\end{aligned}
$$

Recalling that, by (14), we have $-\frac{\partial \hat{x} / \partial \tau_{1}^{H}}{\partial \hat{x} / \partial \tau_{x}^{H}}=y^{\prime}(\hat{x})$, the first condition in (19) can be derived by multiplying the condition $\partial W^{H} / \partial \tau_{x}^{H}=0$ by $y^{\prime}(\hat{x})$ and adding the resulting expression to the condition $\partial W^{H} / \partial \tau_{1}^{H}=0$. We present the Nash conditions in this form in order to facilitate comparison with the efficiency conditions derived in the next section.

Straightforward manipulation of these first-order conditions delivers the following expression for the choice of $\tau_{1}^{H}$ :

$$
\hat{\tau}_{1}^{H N}=-\frac{\left(1-\frac{\gamma^{H}}{2}\right) \hat{x}\left[\frac{y(\hat{x})}{\hat{x}}-y^{\prime}(\hat{x})\right]}{\left|\partial D_{1} / \partial p_{1}^{H}\right|},
$$

which naturally reduces to the analogous equation (10) in the Benchmark Model when $\gamma^{H}=1$. Notice that for low enough $\gamma^{H}$ (in particular $\gamma^{H}<2$ ), the home government continues to find it optimal in the Nash equilibrium to set a positive export tax (or import subsidy) on the final good. Nevertheless, when the weight that the home government places on producer surplus becomes sufficiently high (i.e., $\gamma^{H}>2$ ), $\hat{\tau}_{1}^{H N}$ flips sign according to (10) and (20) and becomes positive. In such a case, the home government puts in place a Nash trade policy that leads to an increase in the domestic price of the final good (i.e., an import tariff or export subsidy). As we have shown above, these policies tend to transfer surplus from the home country to the foreign country, but a sufficiently politically influenced home government is willing to allow this because consumers bear a disproportionate part of the cost of this rent-dissipation.

\footnotetext{
${ }^{22}$ It is straightforward to show that our introduction of political economy into the Benchmark Model does not create a reason for $F$ to utilize $\tau_{1}^{F}$, and so we continue to set $p_{1}^{F}=1$ and focus only on the choices of $\tau_{1}^{H}, \tau_{x}^{H}$ and $\tau_{x}^{F}$.
} 
Further manipulation of the first-order conditions also delivers

$$
\hat{\tau}_{x}^{F N}=\frac{\left(\frac{\gamma^{F}}{2}-1\right) \hat{x}}{\partial \hat{x} / \partial \tau_{x}^{F}},
$$

which indicates that for large enough $\gamma^{F}$ (in particular $\gamma^{F}>2$ ), the foreign government no longer sets an export tax in the Nash equilibrium but rather chooses to subsidize exports of intermediate inputs. Intuitively, although a subsidy reduces foreign tariff revenue by an amount which is strictly larger than the amount by which foreign profits increase, a sufficiently politically influenced foreign government weights the latter effect disproportionately more, and thus sets a positive export subsidy in the Nash equilibrium.

The fact that the magnitude and even the sign of Nash policies are sensitive to political economy considerations is not particularly surprising: analogous findings are reported for example in Grossman and Helpman (1994) and Bagwell and Staiger (2002, Chapter 10). This suggests that the "positive" predictions of our model regarding the types of instruments that governments will use in equilibrium are not always robust to the presence of political-economy concerns. By the same token, however, the fact that import subsidies and export taxes are rarely observed in the real world should not be interpreted as invalidating the empirical relevance of the trade policy inefficiencies highlighted by our Benchmark Model.

\subsection{Politically Efficient Policies}

In light of the impacts that political economy concerns can have on Nash policies in the Benchmark Model, a natural question is whether our central results regarding the inefficiency of Nash policies and the role of trade agreements are robust to the inclusion of political economy considerations. For instance, as we have observed, a sufficiently high weight on home producer surplus (when $\gamma^{H}>2$ ) leads the home government to place an import tariff/export subsidy on the final good, resulting in a Nash trade policy that raises the domestic price of the final good: this suggests that the domestic final good price could therefore be too high in the Nash equilibrium if political economy motives are sufficiently strong. And similarly, it seems possible that the use of export subsidies by the foreign government (when $\gamma^{F}>2$ ) could lead to excessive trade in intermediate inputs.

In order to asses the nature of the inefficiencies associated with Nash equilibrium trade policies when political economy motives are present, we first need to characterize the efficient policies in the presence of political biases. It is straightforward to verify that the efficient policy choices of the two governments (i.e., the policies $\tau_{x} \equiv \tau_{x}^{H}+\tau_{x}^{F}$ and $\tau_{1}^{H}$ that maximize the sum of home and foreign welfare when evaluated in light of the objectives of the governments) must satisfy the following two 
first-order conditions: ${ }^{23,24}$

$$
\begin{aligned}
\frac{\partial W^{W}}{\partial \tau_{1}^{H}} & =0 \Rightarrow \tau_{1}^{H} \frac{\partial D_{1}}{\partial p_{1}^{H}}+\left(\frac{1}{2}\left(\gamma^{H}+\gamma^{F}\right)-1\right) \hat{x}\left[\frac{y(\hat{x})}{\hat{x}}-y^{\prime}(\hat{x})\right]=0, \text { and } \\
\frac{\partial W^{W}}{\partial \tau_{x}} & =0 \Rightarrow\left(1-\frac{1}{2}\left(\gamma^{H}+\gamma^{F}\right)\right) \hat{x}+\left[\gamma^{H}+\tau_{x}-\tau_{1}^{H} y^{\prime}(\hat{x})\right] \frac{\partial \hat{x}}{\partial \tau_{x}}=0 .
\end{aligned}
$$

The first expression in (21) defines the globally efficient level of $\tau_{1}^{H}$ for delivering the efficient volume of input trade $\hat{x}$. The second expression in (21) then ensures that $\tau_{x}$ is set so that the volume of input trade $\hat{x}$ is indeed efficient.

When political economy motives are absent $\left(\gamma^{H}=1=\gamma^{F}\right)$, the first expression in (21) confirms that it is globally efficient to set $\tau_{1}^{H}=0$ and rely solely on $\tau_{x}$ to achieve the efficient volume of input trade; the second expression in (21) then implies that it is efficient to set $\tau_{x}=-1$, thereby achieving $y^{\prime}(\hat{x})=1$ and satisfying global efficiency as we have seen earlier. But when political economy motives are present $\left(\gamma^{H}>1\right.$ and/or $\left.\gamma^{F}>1\right)$, the situation is different. Most strikingly, according to the first expression in (21), efficiency requires $\tau_{1}^{H}>0$. Evidently, the implied redistribution from $H$ 's consumers to $H$ 's producers and $F$ 's suppliers which is associated with at least a small $\tau_{1}^{H}>0$ is valued as long as $\gamma^{H}>1$ and/or $\gamma^{F}>1$. This suggests that, in the presence of strong political economy forces, the Nash choice of $\tau_{1}^{H}$ need not be too high relative to its efficient level simply because those forces are strong enough to imply $\hat{\tau}_{1}^{H N}>0$.

In fact, comparing the first Nash expression in (19) to the first efficiency condition in (21), it can be seen that the two expressions are identical except for the absence from (19) of the term

$$
\left(\frac{\gamma^{F}}{2}\right) \hat{x}\left[\frac{y(\hat{x})}{\hat{x}}-y^{\prime}(\hat{x})\right]>0
$$

Therefore, the first-order condition that defines the globally efficient level of $\tau_{1}^{H}$ for delivering the efficient volume of input trade $\hat{x}$ is positive when evaluated at the Nash taxes, and we can thus conclude that the Nash equilibrium choice of $\tau_{1}^{H}$ is inefficiently low, just as in the Benchmark

\footnotetext{
${ }^{23}$ Defining the efficiency frontier in this way when political economy motives are present fits well with the "memberdriven" nature of the WTO, and it is the approach to evaluating the performance of trade agreements taken by most of the literature, but it is not the only approach. An alternative (pursued for example by Aghion, Antràs, and Helpman, 2007 and by Ornelas, 2008) is to evaluate the performance of trade agreements on the basis of whether or not the agreement guides governments to a point on an efficiency frontier that is defined with regard to a set of preferences that are unrelated to government preferences (e.g., the maximization of real world income). Such an approach would have some potentially interesting implications in the current setting, because politically motivated governments tend to adopt trade policies that promote producer surplus, and this tends to lead to levels of input production that are increasing in the political weight $\gamma$. In a world in which input production is too low as a result of hold up, the policy bias of politically motivated governments could therefore have some attractive consequences from the perspective of real world income. In principle, governments with a particular set of political preferences could adopt policies in the Nash equilibrium which deliver efficient levels of input production in the sense of achieving $\hat{x}=x^{E}$. Nevertheless, in general there is no reason to expect that political pressures would align themselves in this particular way, and so even from this perspective there would as a general matter be inefficiencies in the Nash equilibrium which a trade agreement could correct.

${ }^{24}$ In an analogous fashion to (19), the first condition in (21) may be derived using (14) by multiplying the condition $\partial W^{W} / \partial \tau_{x}=0$ by $y^{\prime}(\hat{x})$ and adding the resulting expression to the condition $\partial W^{W} / \partial \tau_{1}^{H}=0$.
} 
Model.

Similarly, evaluating the second efficiency expression in (21) - which defines the globally efficient level of $\tau_{x}$ and implied volume of input trade $\hat{x}$ - at the Nash taxes, we obtain:

$$
\left(1-\frac{1}{2}\left(\gamma^{H}+\gamma^{F}\right)\right) \hat{x}-\left(2-\frac{1}{2}\left(\gamma^{H}+\gamma^{F}\right)\right) \hat{x}=-\hat{x}<0 .
$$

This implies that the Nash level of $\tau_{x}$ is too high - and therefore that the input trade volume is also inefficiently low - again just as in the Benchmark Model.

These results confirm that the inefficiencies associated with the Nash equilibrium as described in Proposition 4 and the role of a trade agreement as described in Proposition 5 still apply. In particular, even when governments are motivated by political-economy concerns, in the presence of offshoring the role of a trade agreement is to (i) secure the adoption of input trade policies that expand input trade volume to the internationally efficient level; and (ii) secure the adoption of final-good trade policies in $H$ that raise the local price of the final good in $H$ 's market to the internationally efficient level.

\subsection{A Modified Terms-of-Trade Interpretation}

Although we have assumed that both countries are small in world markets, our model of offshoring has input prices determined by the outcome of bilateral negotiations between producers and suppliers, and thus a government can use trade policy to move the terms of exchange in favor of the firms in its particular country. Viewed from this perspective, the underlying problem that leads to the inefficiencies identified in Proposition 4 - and therefore that determines the role of a trade agreement in the presence of offshoring according to Proposition 5 - thus appears to be closely related to the underlying problem identified by the terms-of-trade theory, even though as we have confirmed in the Corollary 1 to Proposition 5 there are some important differences in the nature of the inefficiencies that result. We now explore further the link with the terms-of-trade theory, in order to make precise where our model can and cannot be given a (modified) terms-of-trade interpretation.

To this end, we begin by defining the international price of the input $x$, which we denote by $p_{x}^{*}$. In words, $p_{x}^{*}$ is the (untaxed) price negotiated in stage 3 for the exchange of inputs between the foreign supplier and the home producer. It is easy to see that in the Benchmark Model this price is given by $p_{x}^{*}=\pi^{F} / \hat{x}+\left(1+\tau_{x}^{F}\right)$, which can be written as

$$
p_{x}^{*}=p_{x}^{*}\left(\hat{x}, \tau_{1}^{H}, \tau_{x}^{H}, \tau_{x}^{F}\right) \equiv \frac{1}{2}\left(1+\tau_{1}^{H}\right) \frac{y(\hat{x})}{\hat{x}}-\frac{1}{2}\left(\tau_{x}^{H}-\tau_{x}^{F}\right),
$$

where, for notational ease, we suppress the dependence of $\hat{x}$ on $\tau_{1}^{H}, \tau_{x}^{H}$ and $\tau_{x}^{F}$ indicated by (14).

Of particular interest are the impacts of trade policies on the international price of $x$ when the equilibrium volume of input trade $\hat{x}$ is held fixed. From (24), it is direct to confirm that these impacts are given by the partial derivatives $\partial p_{x}^{*} / \partial \tau_{1}^{H}=\frac{1}{2} y(\hat{x}) / \hat{x}, \partial p_{x}^{*} / \partial \tau_{x}^{H}=-\frac{1}{2}$ and 
$\partial p_{x}^{*} / \partial \tau_{x}^{F}=\frac{1}{2}$. Notice that, when the home government reduces $\tau_{1}^{H}$, the pure international rent shifting it accomplishes can then be written, using these partial derivatives, as $\hat{x} \cdot \partial p_{x}^{*} / \partial \tau_{1}^{H}$, and when it increases $\tau_{x}^{H}$ the associated rent shifting is given by $-\hat{x} \cdot \partial p_{x}^{*} / \partial \tau_{x}^{H}$. Similarly, when the foreign government increases $\tau_{x}^{F}$, the pure international rent shifting is given by $\hat{x} \cdot \partial p_{x}^{*} / \partial \tau_{x}^{F}$. These magnitudes are of interest because they isolate the "bad" - i.e., pure rent-shifting - impacts that intervention can have on the terms of trade from the "good" impacts that are associated with bringing the equilibrium volume of input trade $\hat{x}$ up to internationally efficient levels. ${ }^{25}$

We now borrow terminology from Bagwell and Staiger (1999), and define politically optimal policies as those policies that would hypothetically be chosen by governments unilaterally if (i) the home government placed zero value on the shifting of foreign surplus $\left(\hat{x} \cdot \partial p_{x}^{*} / \partial \tau_{1}^{H}\right)$ that it achieves with a decrease in $\tau_{1}^{H}$; (ii) the home government placed zero value on the shifting of foreign surplus $\left(-\hat{x} \cdot \partial p_{x}^{*} / \partial \tau_{x}^{H}\right)$ that it achieves with an increase in $\tau_{x}^{H}$; and (iii) the foreign government placed zero value on the shifting of home surplus $\left(\hat{x} \cdot \partial p_{x}^{*} / \partial \tau_{x}^{H}\right)$ that it achieves with an increase in $\tau_{x}^{F}$. With politically optimal tariffs defined in this way, we may ask whether politically optimal tariffs are efficient, and thereby explore whether the Nash inefficiencies identified in Proposition 4 can be given a modified terms-of-trade interpretation, according to which the fundamental problem faced by governments in designing their trade agreement is to find ways to eliminate the "bad" terms-of-trade manipulation while maintaining/encouraging the "good," and in so doing play the role identified in Proposition 5.

Using (24), the first-order conditions that define the politically optimal policies $\hat{\tau}_{1}^{H P O}, \hat{\tau}_{x}^{H P O}$, and $\hat{\tau}_{x}^{F P O}$ can be written as: ${ }^{26}$

$$
\begin{aligned}
\tau_{1}^{H} \frac{\partial D_{1}}{\partial p_{1}^{H}}+\left(\frac{\gamma^{H}-1}{2}\right) \cdot\left[\frac{y(\hat{x})}{\hat{x}}-y^{\prime}(\hat{x})\right] \hat{x} & =0 \\
\left(\frac{1-\gamma^{H}}{2}\right) \hat{x}+\left[\gamma^{H}+\tau_{x}^{H}-\tau_{1}^{H} y^{\prime}(\hat{x})\right] \frac{\partial \hat{x}}{\partial \tau_{x}^{H}} & =0, \text { and } \\
\left(\frac{1-\gamma^{F}}{2}\right) \hat{x}+\tau_{x}^{F} \frac{\partial \hat{x}}{\partial \tau_{x}^{F}} & =0 .
\end{aligned}
$$

By evaluating the second efficiency expression in (21) - which recall defines the globally efficient level of $\tau_{x}$ and implied volume of input trade $\hat{x}$ - at the politically optimal policies defined by (25), it is direct to confirm that $\tau_{x}^{P O} \equiv \hat{\tau}_{x}^{H P O}+\hat{\tau}_{x}^{F P O}$ is indeed efficient. Hence we have:

\footnotetext{
${ }^{25}$ Formally, with the local price of $x$ in the home country defined as $p_{x}^{H} \equiv p_{x}^{*}+\tau_{x}^{H}, H$ 's welfare may be expressed as

$$
\begin{aligned}
W^{H} & =C S\left(p_{1}^{H}\right)+\gamma^{H}\left(p_{1}^{H} \cdot y(\hat{x})-p_{x}^{H} \cdot \hat{x}\right)+\left(p_{1}^{H}-1\right)\left[D_{1}\left(p_{1}^{H}\right)-y(\hat{x})\right]+\left(p_{x}^{H}-p_{x}^{*}\right) \hat{x} \\
& \equiv W^{H}\left(p_{1}^{H}, p_{x}^{H}, p_{x}^{*}, \hat{x}\right) .
\end{aligned}
$$

With $W^{H}$ expressed this way, the "bad" terms-of-trade impacts of a slight increase in $\tau_{x}^{H}$ referred to in the text are given by $\frac{\partial W^{H}}{\partial p_{x}^{*}} \frac{\partial p_{x}^{*}}{\partial \tau_{x}^{H}}=\frac{1}{2} \hat{x}$, while the "good" terms-of-trade impacts referred to in the text are given by $\frac{\partial W^{H}}{\partial p_{x}^{*}} \frac{\partial p_{x}^{*}}{\partial \hat{x}} \frac{\partial \hat{x}}{\partial \tau_{x}^{H}}=$ $\frac{1}{2 y^{\prime \prime}(\hat{x})}\left[\frac{y(\hat{x})}{\hat{x}}-y^{\prime}(\hat{x})\right]$. The analogous expressions for $\tau_{1}^{H}$ and $\tau_{x}^{F}$ can be similarly derived.

${ }^{26}$ The first condition in (25) may be derived in an analogous fashion to that in (19) and (21) - see note 24 .
} 
Proposition 6 In the Benchmark Model, the international inefficiency associated with the Nash choices of input tariffs can be given a modified terms-of-trade interpretation: with regard to input tariffs, the role of a trade agreement is to eliminate the "bad" terms-of-trade manipulation associated with the pursuit of pure international rent-shifting while maintaining the "good" terms-of-trade manipulation inherent in the internationally efficient subsidies to input trade.

We next assess the efficiency properties of the politically optimal choice of Home's final-good tariff $\hat{\tau}_{1}^{H P O}$. Comparing the first politically optimal expression in (25) to the first efficiency condition in (21), it can be seen that the two expressions are identical except for the absence from (25) of the term

$$
\left(\frac{\gamma^{F}-1}{2}\right) \cdot\left[\frac{y(\hat{x})}{\hat{x}}-y^{\prime}(\hat{x})\right] \hat{x}
$$

which is positive if and only if $\gamma^{F}>1$. Therefore, the first-order condition that defines the globally efficient level of $\tau_{1}^{H}$ for delivering the efficient volume of input trade $\hat{x}$ is satisfied when evaluated at the political optimum - and we can thus conclude that the politically optimal choice of $\tau_{1}^{H}$ is efficient - if and only if $\gamma^{F}=1$, so that the foreign government is not motivated by political economy concerns. This implies in turn that the inefficiency associated with the Nash choice of $\tau_{1}^{H}$ cannot be given a modified terms-of-trade interpretation when the foreign government is politically motivated.

Hence, we have:

Proposition 7 In the Benchmark Model, the international inefficiency associated with the home government's Nash choice of final-good tariff can be given a modified terms-of-trade interpretation if and only if the foreign government is not motivated by political economy considerations.

By contrast, as we confirm in Appendix B, politically optimal tariffs are efficient regardless of political economy considerations when input prices are determined by an international market clearing condition. ${ }^{27}$

Proposition 7 carries with it an important implication: in our model of offshoring, the underlying problem that gives rise to the inefficiencies which a trade agreement seeks to resolve becomes more complicated when governments possess political economy motives. In this sense, our model formally identifies a separate "political externality" for a trade agreement to address, somewhat along the lines described in Ethier (2004). ${ }^{28}$ This is in stark contrast to the terms-of-trade theory, where the presence or absence of political economy motives has no impact on the underlying problem that a trade agreement must solve.

\footnotetext{
${ }^{27}$ Note also that, as is reflected in our discussion, it is the foreign political economy forces that prevent the politically optimal choice of $\tau_{1}^{H}$ from being efficient. More generally, however, in the presence of symmetric homesupplier/foreign-producer relationships, political economy forces in either country will interfere with the efficiency properties of the political optimum.

${ }^{28}$ As Ethier (2004, p. 305) puts it, “'Political externalities,' by my definition, arise when policymakers in one country believe that their political status (whatever that might be specified to mean) is directly sensitive, to some degree, to actions by policymakers in another country." See also Bagwell and Staiger (2002, Chapter 2) for a further discussion of these ideas.
} 
The essential difference between the terms-of-trade theory and our theory of offshoring that accounts for this distinction is related to the result reported in the Corollary 1 to Proposition 5, and can again be traced to the difference across the two theories in the way that international prices are determined. According to the terms-of-trade theory, international prices are determined through market clearing conditions, with local prices in each economy then determined by arbitrage conditions that link international prices to local prices through a country's own policies. When countries choose politically optimal policies according to the terms-of-trade theory, they therefore ensure that the local-price effects of small adjustments in the policies of their trading partners can have no first-order effect on their welfare, because these local price effects could already have been generated by their own policy adjustments, and the first-order-conditions that define their politically optimal policies ensure that these welfare impacts are zero (see Appendix B for details). By contrast, in our theory of offshoring, international prices are determined by bilateral bargaining between foreign suppliers and home producers, and given the more complex channels through which a trading partner's policies can induce local effects in a country's economy, the first-order conditions that determine a country's politically optimal policies cannot - except for the special case in which governments maximize real national income - ensure that the welfare effects will be zero, because there is no longer any guarantee that the local effects of a trading partner's policy adjustments could have been generated by a country's own policy adjustments.

Notice also that this finding reinforces an observation we made earlier, that the increasing prevalence of offshoring is likely to complicate the task of a trade agreement. Here, the complication is associated with the interaction between offshoring and political economy forces: as Proposition 7 indicates, when these two elements are present, the underlying problem that a trade agreement must address varies with the political preferences of member governments. As a consequence, under the view that governments operate in the presence of important political economy forces, the increasing prevalence of offshoring is likely to make it increasingly difficult for governments to rely on simple and general rules - such as reciprocity and non-discrimination - to help them solve their trade-related problems.

\section{Sensitivity}

In this section we consider the generality of our central findings to various alternative modeling assumptions. For simplicity, we return to a setting in which governments do not possess political economy motives.

\subsection{General Bargaining Power}

In the Benchmark Model we have assumed that all bargaining between home producers and foreign suppliers is characterized by symmetric Nash bargaining, with each party capturing one-half of the ex-post gains from trades. We have also assumed that the lack of an ex-post contractual agreement leaves both parties with no time to attempt to transact with alternative producers, and thus the 
outside options in the bargaining are equal to 0 . We now explore the robustness of our results to more general bargaining assumptions. Below we consider the case of general bargaining power and the introduction of a secondary market for inputs in $H$. In Appendix A.3, we also consider the possibility that the secondary market for the foreign supplier is located in the foreign country. In each case, we show that helping governments solve the international hold-up problem between producers and suppliers and avoid the policy distortions that would be introduced by attempts to extract bargaining surplus from foreign firms remain the fundamental purposes of a trade agreement in the model.

In order to explicitly derive the payoffs associated with the secondary market we now assume that good 1 comes in two types, a customized type $T$ and a generic type $G$, and that consumer preferences are given by

$$
U^{j}=c_{0}^{j}+u\left(c_{1_{T}}^{j}+\delta c_{1_{G}}^{j}\right), \quad 0<\delta<1 .
$$

Note that the preferences in (27) are such that consumers are willing to buy both types of good 1 only if the price of the generic relative to that of the customized type is equal to $\delta$. This is analogous to consumers perceiving the two goods as perfect substitutes up to a quality shifter. By an appropriate choice of units, we can set the (fixed) price of customized inputs on world markets equal to 1 , and that of generic inputs to $\delta$.

The technology for producing final goods and intermediate inputs is as in our Benchmark Model. The only difference between the two types of good 1 is that the production of a generic good $G$ uses an intermediate input $x$ that is not customized to the producer's needs.

The game we consider is a straightforward extension to that in our Benchmark Model that incorporates a secondary market for inputs and generalized Nash bargaining. The sequence of events is as follows:

stage 1. The unit measure of producers in $H$ and suppliers in $F$ are randomly matched, producing a unit measure of matches. Each agent decides whether to stay with his match or exit the market. In the former case, the producer provides the supplier with a list of customized input specifications. In the latter case, each producer obtains his ex-ante outside option (equal to zero).

stage 2. Each supplier decides on the amount $x$ of customized input to be produced (at marginal cost of 1) - the marginal cost of production for a generic input (not customized to the matched producer's needs) is the same, so there is no benefit in not customizing the input for the matched producer at this point.

stage 3. Each producer-supplier pair bargains over the price of the intermediate input. We consider the generalized Nash bargaining solution with weights $\alpha$ and $(1-\alpha)$ for the home producer and foreign supplier, respectively, where $\alpha \in(0,1)$.

stage 4. A small number (formally, a measure-zero countable infinity) $n$ of the bilateral pairs are exogenously dissolved and randomly rematched in a secondary market. They bargain again 
according the same generalized Nash bargaining solution as in stage 3. No further inputs can be produced; the amount produced in stage 2 is perceived as generic in the secondary market because it was tailored to another producer's specifications with probability one.

stage 5. Each producer in $H$ imports $x$ from its partner-supplier and produces the final good with the acquired $x$, and payments agreed in stages 3 and 4 are settled.

We focus directly on deriving Nash policy choices, assuming as before that the home and foreign governments select their respective tariffs simultaneously in a prior stage 0. Note that given the specification of the secondary market in stage 4, it is easy to see that the breakup of a single bargaining pair in stage 3 would result in each member of the pair being rematched with probability 1 with a random partner in stage 4 , and therefore that stage 4 implies an outside option equal to $\alpha\left(\delta\left(1+\tau_{1}^{H}\right) y(x)-\left(\tau_{x}^{H}+\tau_{x}^{F}\right) x\right)$ for the final-good producer and $(1-\alpha)\left(\delta\left(1+\tau_{1}^{H}\right) y(x)-\left(\tau_{x}^{H}+\tau_{x}^{F}\right) x\right)$ for the supplier. These expressions are valid provided they are non-negative, and here and throughout this section we characterize results for the case where these non-negativity constraints are nonbinding. In Appendix A.2 we consider the cases where a non-negativity constraint is binding (so that the associated payoff is zero), and show that our qualitative results carry through for those cases as well. ${ }^{29}$

Following analogous steps as in previous sections, it is easy to see that generalized Nash bargaining in stage 3 will leave the final-good producer in $H$ with a payoff equal to $\alpha\left(1+\tau_{1}^{H}\right) y(x)-$ $\alpha\left(\tau_{x}^{H}+\tau_{x}^{F}\right) x$, with the supplier in $F$ now receiving a stage-3 payoff of $(1-\alpha)\left(1+\tau_{1}^{H}\right) y(x)-$ $(1-\alpha)\left(\tau_{x}^{H}+\tau_{x}^{F}\right) x$. As a result, we have that the stage-2 choice of $\hat{x}$ is now defined by

$$
(1-\alpha)\left(1+\tau_{1}^{H}\right) y^{\prime}(\hat{x})=1+(1-\alpha)\left(\tau_{x}^{H}+\tau_{x}^{F}\right)
$$

and hence the stage-1 payoffs of the home and foreign firm are given by

$$
\begin{aligned}
& \pi^{H}=\alpha\left(1+\tau_{1}^{H}\right) y(\hat{x})-\alpha\left(\tau_{x}^{H}+\tau_{x}^{F}\right) \hat{x}, \text { and } \\
& \pi^{F}=(1-\alpha)\left(1+\tau_{1}^{H}\right) y(\hat{x})-(1-\alpha)\left(\tau_{x}^{H}+\tau_{x}^{F}\right) \hat{x}-\hat{x} .
\end{aligned}
$$

Home and foreign welfare may now be written as

$$
\begin{aligned}
W^{H} & =C S\left(p_{1}^{H}\right)+\pi^{H}+\tau_{1}^{H}\left[D_{1}\left(p_{1}^{H}\right)-y(\hat{x})\right]+\tau_{x}^{H} \hat{x}, \text { and } \\
W^{F} & =C S(1)+\pi^{F}+\tau_{x}^{F} \hat{x} .
\end{aligned}
$$

The first-order conditions that define the Nash policies $\hat{\tau}_{1}^{H N}, \hat{\tau}_{x}^{H N}$, and $\hat{\tau}_{x}^{F N}$ can be manipulated

\footnotetext{
${ }^{29}$ Beyond determining outside options, stage 4 plays no role in the model, and in particular only the customized type of good 1 will be produced with positive measure in equilibrium.
} 
using (28) to yield ${ }^{30}$

$$
\begin{aligned}
\hat{\tau}_{1}^{H N} & =-\frac{(1-\alpha) \hat{x}\left[\frac{y(\hat{x})}{\hat{x}}-y^{\prime}(\hat{x})\right]}{\left|\partial D_{1} / \partial p_{1}^{H}\right|} \\
\hat{\tau}_{x}^{H N} & =-\frac{\left[\alpha-(1-\alpha) \hat{\tau}_{1}^{H N}\right] y^{\prime}(\hat{x})}{(1-\alpha)}+\frac{\alpha \hat{\tau}_{x}^{F N}}{(1-\alpha)}-\frac{\hat{x}}{\partial \hat{x} / \partial \tau_{x}^{H}}, \text { and } \\
\hat{\tau}_{x}^{F N} & =-\alpha \frac{\hat{x}}{\partial \hat{x} / \partial \tau_{x}^{F}} .
\end{aligned}
$$

By setting $\alpha=1 / 2$, it is easily verified that these expressions coincide with those of the Benchmark Model above, where symmetric Nash bargaining and the absence of a secondary market for inputs was assumed. Considering the case of generalized Nash bargaining allows us to illustrate how the Nash equilibrium policy choices of governments are affected by conditions of ex-post bargaining between foreign suppliers and domestic producers. For instance, the extent to which the Foreign country wants to use export taxes to extract revenue from Home producers is tightly related to their bargaining power; in fact, a prerequisite for export taxes to be used by the foreign country is for this country's suppliers to have weak (or at least less-than-complete) bargaining power in the market for inputs. ${ }^{31}$

Leaving aside the differences that the specifics of the bargaining process make to the equilibrium Nash policy choices, we emphasize two general results that continue to hold regardless of the value of $\alpha$. First, the international hold-up problem persists and the volume of international input trade is inefficiently low as a consequence. To see this, one can manipulate the first-order conditions and use the expression for $\partial \hat{x} / \partial \tau_{x}^{H}$ and $\partial \hat{x} / \partial \tau_{x}^{F}$ implied by (28) to derive

$$
y^{\prime}(\hat{x})=1-\frac{\hat{x}}{\partial \hat{x} / \partial \tau_{x}^{H}}>1
$$

which implies that $\hat{x}<x^{E}$. Second, it is evident that $\hat{\tau}_{1}^{H N}<0$ for $\alpha<1$, and so our model continues to predict that there are distortions in the final good market ( $p_{1}^{H}$ is too low) that arise as a result of the home-country's attempts to extract bargaining surplus from foreign suppliers. The purpose of a trade agreement therefore remains to help governments better solve these two

\footnotetext{
${ }^{30}$ Throughout the extension section, we simply assume that second-order conditions are met.

${ }^{31}$ In fact what is key is that foreign suppliers have less than full bargaining power in the secondary market for inputs. To see this, consider the case in which there is generalized Nash bargaining in both stages 3 and 4 , but with potentially different bargaining weights $\alpha_{P}$ and $\alpha_{S}$, respectively. In such a case, the Nash tariff choices are characterized by the following conditions:
}

$$
\begin{aligned}
\hat{\tau}_{1}^{H N} & =\frac{(1-\bar{\alpha}) \hat{x}\left[y^{\prime}(\hat{x})-\frac{y(\hat{x})}{\hat{x}}\right]}{-\partial D_{1} / \partial p_{1}^{H}}, \\
\hat{\tau}_{x}^{H N} & =-\frac{\left[\bar{\alpha}-(1-\bar{\alpha}) \hat{\tau}_{1}^{H N}\right] y^{\prime}(\hat{x})}{\left(1-\alpha_{S}\right)}+\frac{\alpha_{S} \hat{\tau}_{x}^{F N}}{\left(1-\alpha_{S}\right)}-\frac{\hat{x}}{\partial \hat{x} / \partial \tau_{x}^{H}}, \text { and } \\
\hat{\tau}_{x}^{F N} & =-\alpha_{S} \frac{\hat{x}}{\partial \hat{x} / \partial \tau_{x}^{F}}
\end{aligned}
$$

where $\bar{\alpha} \equiv \alpha_{S} \delta+\alpha_{P}(1-\delta)$. It is apparent that $\hat{\tau}_{x}^{F N}>0$ only if $\alpha_{S}>0$. 
problems, just as in our Benchmark Model. ${ }^{32}$

It is also possible to use the extended model developed in this section to make a broader point. Up to now we have not taken a stance as to whether the home producer and foreign supplier are vertically related or not. According to the transaction-cost approach to the boundaries of the firm (c.f., Coase, 1936, Williamson, 1985), vertical integration would arise precisely when the hold-up inefficiencies that we have modelled above become large relative to the larger "governance" costs of running an integrated organization. According to that view, our novel rationale for trade agreements would disappear because production of the final good could then be characterized by neoclassical production theory. ${ }^{33}$ Nevertheless, the property-rights approach to the theory of the firm (c.f., Grossman and Hart, 1986, Hart and Moore, 1990) has persuasively argued that firm boundaries are better understood as determining the relative bargaining power of producers (via the allocation of residual rights of control inherent in the ownership of productive physical assets) rather than as affecting the space of contracts available to economic agents. Under this interpretation, the rationale for trade agreements that we propose in this paper would very much apply to vertically integrated cross-border production relationships. A crude way to capture the essence of the property-rights theory of the firm in terms of the extended model developed in this section would be to associate international outsourcing relationships with a low value of $\alpha$ (the bargaining power of home producers) as compared to the value of $\alpha$ applying to international insourcing relationships. With this interpretation, our finding that the fundamental purpose of a trade agreement does not depend on the value of $\alpha$ then suggests as well that the presence or absence of vertical integration would not alter the fundamental purpose of a trade agreement. ${ }^{34}$

\subsection{Ex-Ante Lump-Sum Transfers}

Our Benchmark Model rules out ex-ante lump-sum transfers between home producers and foreign suppliers. Although this seems a plausible assumption in our international framework where the promises associated with these transfers may be hard to enforce, it is useful to study the robustness of our results to this assumption. For that purpose, we consider the following modification of stage 1 of our Benchmark Model:

stage 1. The unit measure of producers in $H$ and suppliers in $F$ are randomly matched, producing a unit measure of matches. Each producer in $H$ and its matched supplier in $F$ bargain over

\footnotetext{
${ }^{32}$ It is interesting to note that for the limiting case of $\alpha=1$, we have $\hat{\tau}_{1}^{H N}=0$ and so the final-good market distortions associated with Nash policies disappear. This reflects the fact that the home firm has full stage-3 bargaining power when $\alpha=1$, and so the home government has no reason to distort $\tau_{1}^{H}$ for the purposes of extracting bargaining surplus from foreign firms in this limiting case.

${ }^{33}$ This assumes that home producers could hire foreign suppliers in a competitive market at a given price, which is consistent with the transaction-cost assumption of a frictionless integrated structure (see Grossman and Helpman, 2002 , for a general equilibrium treatment).

${ }^{34}$ This is not to say that the presence or absence of vertically integrated home producers and foreign suppliers would be irrelevant for the nature of trade agreements. On the contrary, to the extent that international factor ownership associated with vertically integrated multinational firms alters the objective functions of each government, the nature of trade agreements could be very much affected (see Blanchard, 2006). Rather, our point is simply that vertical integration does not by itself obviate the need for a trade agreement to address the international hold-up problem.
} 
whether to continue their relationship or not and lump-sum transfers are allowed in the bargaining. This stage-1 bargaining is captured by the generalized Nash bargaining solution with weights $\beta$ and $(1-\beta)$ for the home producer and foreign supplier, respectively, where $\beta \in(0,1)$. If the relationship is terminated, both firms exit; if an agreement is reached, the producer retains the supplier and provides it with a list of customized input specifications.

For simplicity, we assume that the remaining stages of the game are as in the Benchmark Model (and, in particular, all ex-post bargains are governed by symmetric Nash bargaining). This implies that at stage 1 , the home producer and the foreign supplier anticipate that if they reach an agreement, they stand to obtain a joint payoff of

$$
\pi^{H}+\pi^{F}=\left(1+\tau_{1}^{H}\right) y(\hat{x})-\left(\tau_{x}^{H}+\tau_{x}^{F}\right) \hat{x}-\hat{x}
$$

where $\hat{x}$ is given by

$$
\frac{1}{2}\left(1+\tau_{1}^{H}\right) y^{\prime}(\hat{x})=1+\frac{1}{2}\left(\tau_{x}^{H}+\tau_{x}^{F}\right) .
$$

Instead, if an agreement is not reached, both firms exit and are left with a payoff equal to 0 . In Appendix A.2, we show that $\pi^{H}+\pi^{F}>0$, which implies that all pairs reach an agreement at stage 1. Note, however, that because of the lump-sum transfers, the division of profits between home producers and foreign suppliers is now detached from the ex-post bargaining solution. ${ }^{35}$ In particular, we have:

$$
\begin{aligned}
& \pi^{H}=\beta\left[\left(1+\tau_{1}^{H}\right) y(\hat{x})-\left(\tau_{x}^{H}+\tau_{x}^{F}\right) \hat{x}-\hat{x}\right], \text { and } \\
& \pi^{F}=(1-\beta)\left[\left(1+\tau_{1}^{H}\right) y(\hat{x})-\left(\tau_{x}^{H}+\tau_{x}^{F}\right) \hat{x}-\hat{x}\right] .
\end{aligned}
$$

The values of home and foreign welfare are still given by equation (29) with the new profit levels $\pi^{H}$ and $\pi^{F}$ applying.

We can next turn to study the Nash equilibrium policy choices of this variant of the model with lump-sum transfers. Manipulating the first-order conditions related to the choices of $\hat{\tau}_{1}^{H N}, \hat{\tau}_{x}^{H N}$, and $\hat{\tau}_{x}^{F N}$ delivers:

$$
\begin{aligned}
\hat{\tau}_{1}^{H N} & =-\frac{(1-\beta) \hat{x}\left[\frac{y(\hat{x})}{x}-y^{\prime}(\hat{x})\right]}{\left|\partial D_{1} / \partial p_{1}^{H}\right|}, \\
\hat{\tau}_{x}^{H N} & =-(1-\beta) \frac{\hat{x}}{\partial \hat{x} / \partial \tau_{x}^{H}}-\beta+\hat{\tau}_{1}^{H N} y^{\prime}(\hat{x}), \text { and } \\
\hat{\tau}_{x}^{F N} & =-\beta \frac{\hat{x}}{\partial \hat{x} / \partial \tau_{x}^{F}}-(1-\beta) .
\end{aligned}
$$

Again we emphasize two general results that continue to hold for any $\beta \in(0,1)$. First, the international hold-up problem persists and the volume of international input trade is inefficiently

\footnotetext{
${ }^{35}$ Still, the equilibrium level of $\hat{x}$ will be identical to that in the Benchmark Model, since foreign suppliers choose $\hat{x}$ to maximize ex-post payoffs (thus ignoring ex-ante payments).
} 
low as a consequence. To see this, one can manipulate the first-order conditions to derive

$$
y^{\prime}(\hat{x})=1-\frac{\hat{x}}{\partial \hat{x} / \partial \tau_{x}^{F}}>1
$$

which again implies that $\hat{x}<x^{E}$. Second, it is evident that $\hat{\tau}_{1}^{H N}<0$ for $\beta<1$, and so our model continues to predict that there are distortions in the final good market ( $p_{1}^{H}$ is too low) that arise as a result of the home-country's attempts to extract bargaining surplus from foreign suppliers. Once again therefore, the purpose of a trade agreement remains to help governments better solve these two problems, just as in our Benchmark Model. ${ }^{36}$

\subsection{Multiple Foreign Countries and Search Costs}

Our analysis has been restricted to situations in which home producers can only search for suppliers in $F$. It is straightforward to show that at least some of our results could be overturned when this restriction is relaxed. To illustrate this in the starkest possible way, we consider again the variant of the Benchmark Model described in the previous section, with lump-sum ex-ante transfers available to producers.

Let us focus on the limiting case in which home producers have full bargaining power, that is $\beta=1$. In such a case, we have $\hat{\tau}_{1}^{H N}=0$ and $\hat{\tau}_{x}^{H N}=-1$, which indicate that if the foreign government followed a policy of free trade, the Nash equilibrium policies would coincide with the second-best ones and there would be no need for a trade agreement. The intuition is straightforward: the home government would in such a case be internalizing the whole gains from trade, and thus its policy choices would coincide with those of a world social planner facing the same constraints on the choice of $\hat{x}$. But the foreign government will not remain passive, and in fact sets a positive export tax equal to $\hat{\tau}_{x}^{F N}=-\hat{x} /\left(\partial \hat{x} / \partial \tau_{x}^{F}\right)>0$, which is equivalent to the export tax that maximizes export $\operatorname{tax}$ revenue $\tau_{x}^{F} \hat{x}$. The logic is as follows: absent government intervention, foreign input suppliers gain nothing from their bilateral relationships with home final good producers when $\beta=1$, and as a consequence welfare in $F$ is unaffected by the hold-up problem. This gives the foreign government no incentive to intervene to try to fix the problem. Instead, as the foreign government can commit to an export policy before its suppliers are matched with producers in the home country (i.e., before stage 1), its only goal is to collect maximal trade tax revenue from the exportation of $x$, because the incidence of its tax is borne completely by final good producers in $H$ (through a reduction in the transfer that can be extracted from the foreign supplier by the domestic producer).

Hence, even in this limiting case of the Benchmark Model extended to permit lump-sum ex-ante transfers, international efficiency is not reached. Notice, though, that it is not reached because the foreign government has an incentive to set a positive export tax in that case.

Now consider the case in which there is a second "foreign" country, denoted by $S$ for "South,"

\footnotetext{
${ }^{36}$ As with the case of stage-3 bargaining power discussed in note 32 , in the limiting case of $\beta=1$, we have $\hat{\tau}_{1}^{H N}=0$ and so the final-good market distortions associated with Nash policies disappear. This reflects the fact that the home firm has full stage-1 bargaining power when $\beta=1$, and so the home government has no reason to distort $\tau_{1}^{H}$ for the purposes of extracting bargaining surplus from foreign firms in this limiting case.
} 
with an additional unit measure of potential suppliers identical to those in $F$. Assume that $F$ and $S$ are identical in every other respect, including preferences, technology and bargaining strength. Under these circumstances and as long as $\tau_{x}^{F}>\tau_{x}^{S}$, all home producers will prefer to match with southern suppliers over suppliers in $F$. As a result, the government in $F$ will have an incentive to reduce its export tax below the southern one. Pushing this argument further, it is straightforward to show then that the optimal foreign and southern export taxes that emerge from this variant of the model are $0 .{ }^{37}$ As a result, in this extended variant of the Benchmark Model, home producers internalize the whole gains from the offshoring relationship, and the home government chooses the first-best policies described in Proposition 2. The rationale for a trade agreement in this extended variant of the Benchmark Model has vanished.

This example, however, is special in a number of ways. To begin with, the assumption that $F$ and $S$ are symmetric is not innocuous: if one of the two foreign countries has a comparative advantage in supplying inputs, it can (and will) maintain a positive export tax (analogous to "limit pricing" in the case of Bertrand competition among firms), and the result of our Benchmark Model is then preserved. More importantly, the structure of the example above imposes that home producers find a match with probability one, no matter where they search for suppliers. As emphasized by Grossman and Helpman (2005), an important feature of offshoring relationships is the costly search for suitable partners. The same characteristics that make offshoring relationships contractually difficult (i.e., customization, international enforceability of contracts, etc.) preclude the existence of a frictionless competitive market for inputs or for suppliers.

To bring these issues into our analysis in a simple way, we now assume that $F$ contains a measure $\rho$ of potential suppliers, while $S$ contains a measure $1-\rho$. If $k$ home producers search for matches in $F$, the total measure of successful matches is given by the matching function $m(k, \rho) \leq \min \{k, \rho\}$, where $m(\cdot)$ is increasing in both arguments and features constant returns to scale. For simplicity, we assume that $S$ adopts a laissez-faire policy. Will this force $F$ to give up the use of an export tax? As we now demonstrate, the answer is "No."

To show this, we begin by noting that, for home producers to be indifferent between searching in $F$ and in $S$, we need:

$$
\frac{m(k, \rho)}{k}\left(y\left(\hat{x}^{F}\right)-\tau_{x}^{F} \hat{x}^{F}\right)=\frac{m(1-k, 1-\rho)}{1-k} y\left(\hat{x}^{S}\right)
$$

where $\hat{x}^{F}$ is such that $y^{\prime}\left(\hat{x}^{F}\right)=1+\tau_{x}^{F}$, while $\hat{x}^{S}$ is such that $y^{\prime}\left(\hat{x}^{S}\right)=1$. Equation (30) defines a negative relationship between $k$ and $\tau_{x}^{F}$ : intuitively, an increase in the foreign export tax should be matched by an increase in the probability of finding a match in that country, which in turn requires a decrease in the measure of home producers searching for partners in that country. To see this formally, note that using the assumption of constant-return-to scale in the matching function, we

\footnotetext{
${ }^{37}$ The logic is analogous to that behind the fact that Bertrand competition implies marginal-cost pricing.
} 
can write:

$$
\frac{d k}{d \tau_{x}^{F}}=\frac{\left(y^{\prime}\left(\hat{x}^{F}\right)-\tau_{x}^{F}\right)\left(-\partial \hat{x}^{F} / \partial \tau_{x}^{F}\right)+\hat{x}^{F}}{-\frac{\rho \mu^{\prime}(\rho / k)}{k \mu(\rho / k)} \frac{1}{k}\left(y\left(\hat{x}^{F}\right)-\tau_{x}^{F} \hat{x}^{F}\right)-\frac{1}{(1-k)^{2}} \frac{(1-\rho) \mu^{\prime}((1-\rho) /(1-k))}{\mu(\rho / k)} y\left(\hat{x}^{S}\right)}<0
$$

where $\mu(\rho / k) \equiv m(1, \rho / k)$ and thus $\mu^{\prime}(\rho / k)>0$.

In order to explore the implications of this framework for the optimal choice of an export tax in $F$, we first define welfare in $F$ as the sum of consumer surplus and tariff revenue collected from all the matched bilateral pairs:

$$
W^{F}=C S(1)+m(k, \rho) \tau_{x}^{F} \hat{x}^{F}
$$

It thus follows that the optimal choice of $\tau_{x}^{F}$ (denoted $\hat{\tau}_{x}^{F}$ ) will now satisfy:

$$
\frac{\partial W^{F}}{\partial \tau_{x}^{F}}=\frac{\partial m(k, \rho)}{\partial k} \frac{d k}{d \tau_{x}^{F}} \tau_{x}^{F} \hat{x}^{F}+m(k, \rho) \hat{x}^{F}+m(k, \rho) \tau_{x}^{F} \frac{\partial \hat{x}^{F}}{\partial \tau_{x}^{F}}=0
$$

which in turn implies:

$$
\hat{\tau}_{x}^{F}=\frac{\hat{x}^{F}}{-\frac{\partial \hat{x}^{F}}{\partial \tau_{x}^{F}}-\frac{\partial m(k, \rho)}{\partial k} \frac{1}{m(k, \rho)} \frac{d k}{d \tau_{x}^{F}} \hat{x}^{F}}>0 .
$$

In sum, provided that $\frac{d k}{d \tau_{x}^{F}}$ remains bounded, the optimal export tax will be positive. It is straightforward to show that for well-behaved matching functions, the export tax will remain positive even for infinitesimally small countries. In particular, notice from equation (30) that whenever the elasticity of $m(\cdot)$ with respect to both of its arguments is positive, we will have that when $\rho \rightarrow 0$, and hence as $F$ becomes infinitesimally small, $\frac{d k}{d \tau_{x}^{F}}$ goes to 0 as well, and thus

$$
\hat{\tau}_{x}^{F} \rightarrow \frac{\hat{x}^{F}}{-\partial \hat{x}^{F} / \partial \tau_{x}^{F}}
$$

which corresponds to the expression derived in the previous section (and evaluated at $\beta=1$ ) when only $F$ is the source of inputs. ${ }^{38}$

Arguing in this general fashion, it can be seen that the central findings of our Benchmark Model are robust to the introduction of multiple foreign countries where inputs may be sourced and the associated matching frictions that would naturally arise in this setting.

\subsection{Ad Valorem Tariffs}

We next return to the Benchmark Model but depart from the specific tariff analyzed in the previous sections, and consider instead an ad-valorem import tariff on intermediate inputs. We show here that ad valorem tariffs introduce a novel channel through which bargaining between the home

\footnotetext{
${ }^{38}$ In particular, under the maintained assumptions, $\frac{\rho \mu^{\prime}(\rho / k)}{k \mu(\rho / k)}$ is positive and bounded below 1 , while $\frac{(1-\rho) \mu^{\prime}((1-\rho) /(1-k))}{\mu(\rho / k)}$ goes to infinity when $\rho \rightarrow 0$.
} 
producer and foreign supplier can be affected. Despite this novel channel, however, we confirm that the role played by an international trade agreement remains the same.

To this end, with the "international" (foreign exporter) price $p_{x}^{*}$ still denoting the price negotiated in stage 3 for the exchange of intermediate inputs between the foreign supplier and the home producer, we now let $t_{x}^{H}$ and $t_{x}^{F}$ denote, respectively, the home-country and foreign-country taxes on trade in the intermediate good $x$ expressed in ad valorem terms. With this notation we highlight explicitly that the stage-3 negotiation between producer and supplier divides surplus between them by agreeing on the price at which the foreign supplier sells the $x$ units of intermediate input to the home producer.

As will become clear, the novel aspects that arise when tariffs take an valorem rather than specific form apply only to input tariffs; nothing substantive changes if the final good tariffs are expressed in ad valorem terms. Therefore, to focus on the novel aspects of ad valorem tariffs, we now ignore tariffs on the final good and set $\tau_{1}^{H}=\tau_{1}^{F} \equiv 0$. With this assumption, according to the Benchmark Model there would be only one problem for a trade agreement to solve in the presence of specific tariffs on trade in the intermediate input $x$, namely, the elimination of the international hold-up problem, and we now confirm that this remains the case when the tariffs take an ad valorem form.

Specifically, if the producer and supplier reach an agreement in their stage-3 bargaining that specifies a price level $\tilde{p}_{x}^{*}$, then the home-country producer receives a stage-3 payoff of $\omega^{H}=y(x)-$ $\left(1+t_{x}^{H}\right) \tilde{p}_{x}^{*} x$ while the foreign supplier receives a stage-3 payoff of $\omega^{F}=\frac{\tilde{p}_{x}^{*}}{\left(1+t_{x}^{F}\right)} x$. Notice that this implies a bargaining frontier defined by $\omega^{H}=y(x)-\left(1+t_{x}^{H}\right)\left(1+t_{x}^{F}\right) \omega^{F}$ : because the level of the exporter price $p_{x}^{*}$ is used by the home producer and foreign supplier to shift surplus between them, a positive ad valorem import tariff or export tax makes the slope of the bargaining frontier between the home producer and the foreign supplier steeper, while a negative ad valorem tariff (an import or export subsidy) makes the slope of the bargaining frontier flatter. ${ }^{39}$ In effect, then, ad valorem trade taxes penalize the producer and supplier for shifting surplus toward the foreign supplier (with a high $p_{x}^{*}$ ), while ad valorem trade subsidies encourage surplus-shifting in this direction, suggesting a novel channel through which ad valorem trade taxes can affect the severity of the international hold-up problem. This channel is not present when a specific tariff is instead utilized, because the slope of the bargaining frontier between producer and supplier is -1 independent of the level of the specific tariffs $\tau_{x}^{H}$ and $\tau_{x}^{F}$.

On the other hand, if the producer and supplier fail to reach an agreement in their stage-3 bargaining, they will be left with a payoff equal to $0 .{ }^{40}$ The stage-3 Nash bargaining problem

\footnotetext{
${ }^{39}$ We abstract here from the possibility that firms might engage in transfer-pricing-type behavior in order to avoid trade taxes or collect trade subsidies. In our setting, this amounts to assuming that firms do not have other (non-price) means to transfer surplus between them in their bilateral bargain. If they did have such means, then the price they negotiate would be determined completely by the sign of the trade taxes subject only to the ability of governments to regulate such behavior. Even without such means, the firms in our model do respond to government trade taxes by negotiating different prices, but at least when these firms are taken to be engaged in arms-length transactions this would not be interpreted as transfer pricing in the traditional sense.

${ }^{40}$ It would be straightforward to extend the analysis to include a secondary market that generates positive outside options for both types of producers.
} 
between the home producer and foreign supplier can then be characterized as follows:

$$
\begin{aligned}
& \operatorname{Max}_{\omega^{H}, \omega^{F}} \quad \omega^{H} \omega^{F} \\
& \text { s.t. } \omega^{H}=y(x)-\left(1+t_{x}^{H}\right)\left(1+t_{x}^{F}\right) \omega^{F} .
\end{aligned}
$$

The solution to this bargaining problem yields $\omega^{H}=\frac{1}{2} y(x)$ and $\omega^{F}=\frac{1}{2} \frac{y(x)}{\left(1+t_{x}^{H}\right)\left(1+t_{x}^{F}\right)}$, and an implied foreign exporter price of $\hat{p}_{x}^{*}=\frac{\frac{1}{2} y(x)}{\left(1+t_{x}^{H}\right) x}$. The choice of $x$ at stage 2 is then governed by

$$
\frac{1}{2} y^{\prime}(\hat{x})=\left(1+t_{x}^{H}\right)\left(1+t_{x}^{F}\right)
$$

and hence $\hat{x}$ continues to be decreasing in the (ad valorem) tariffs $t_{x}^{H}$ and $t_{x}^{F}$, despite the novel channel through which the ad valorem tariffs affect the bargaining between home producer and foreign supplier. With this, we can now write the stage-1 payoffs of the home and foreign firm as

$$
\begin{aligned}
\pi^{H} & =\frac{1}{2} y(\hat{x}), \text { and } \\
\pi^{F} & =\frac{1}{2} \frac{y(\hat{x})}{\left(1+t_{x}^{H}\right)\left(1+t_{x}^{F}\right)}-\hat{x} .
\end{aligned}
$$

We consider next the Nash tariff choices. With $t_{1}^{H}=t_{1}^{F} \equiv 0$, home and foreign welfare are now given by

$$
\begin{aligned}
W^{H} & =C S(1)+\pi^{H}+t_{x}^{H} \hat{p}_{x}^{*} \hat{x}=C S(1)+\frac{1}{2} y(\hat{x})+\frac{1}{2} \frac{t_{x}^{H} y(\hat{x})}{\left(1+t_{x}^{H}\right)}, \\
W^{F} & =C S(1)+\pi^{F}+\frac{t_{x}^{F}}{1+t_{x}^{F}} \hat{p}_{x}^{*} \hat{x}=C S(1)+\frac{1}{2} \frac{y(\hat{x})}{\left(1+t_{x}^{H}\right)}-\hat{x} .
\end{aligned}
$$

It is direct to show that the first-order condition for $t_{x}^{F}$ implies $y^{\prime}(\hat{x})=2\left(1+t_{x}^{H}\right)$. Hence, to check whether $\hat{t}_{x}^{H N}$ might achieve international efficiency in light of $\hat{t}_{x}^{F N}$, we may observe that, in combination with $\hat{t}_{x}^{F N}$, international efficiency would require $t_{x}^{H}=-\frac{1}{2}$. But differentiating $W^{H}$ with respect to $t_{x}^{H}$ yields

$$
\frac{\partial W^{H}}{\partial t_{x}^{H}}=\frac{1}{2} y^{\prime}(\hat{x}) \frac{\left(1+2 t_{x}^{H}\right)}{\left(1+t_{x}^{H}\right)} \frac{\partial \hat{x}}{\partial t_{x}^{H}}+\frac{1}{2} \frac{y(\hat{x})}{\left(1+t_{x}^{H}\right)^{2}},
$$

which is strictly positive when evaluated at the internationally efficient level of $t_{x}^{H}=-\frac{1}{2}$ : by implication, then, $\hat{t}_{x}^{H N}$ is higher than the internationally efficient level.

Hence, while the mechanisms through which specific and ad valorem tariffs on traded inputs influence the international hold-up problem are distinct, the broad conclusions are the same. Combining this with our earlier observation that the form of the final-good tariff is immaterial, we may conclude that the central findings of our Benchmark Model are robust to the form (ad valorem or 
specific) that tariffs take, despite the different mechanisms that operate in the two environments. ${ }^{41}$

\section{Conclusion}

In this paper, we have initiated the study of trade agreements in the presence of offshoring. Our findings indicate that the rise of offshoring is likely to complicate the task of trade agreements for two specific reasons.

First, in the presence of offshoring the mechanism by which countries can shift the costs of intervention on to their trading partners is more complicated and extends to a wider set of policies than is the case when offshoring of customized inputs is not present. And second, the underlying problem that a trade agreement must address in the presence of offshoring varies with the political preferences of member governments, a complication that does not arise in the absence of offshoring.

As a consequence of the first complication, the increasing prevalence of offshoring makes it likely that effective trade agreements must extend their focus beyond the traditional market access concerns of establishing and maintaining conditions of competition to cover as well the conditions of bargaining: as we have observed, this suggests the need for negotiations that might potentially cover a wide array of internal/domestic measures that have not typically been included in the traditional focus of trade agreements. As a consequence of the second complication, the increasing prevalence of offshoring is likely to make it increasingly difficult for governments to rely on simple and general rules to help them solve their trade-related problems: this suggests that rules such as reciprocity and non-discrimination, which have been pillars of the multilateral trading system under the GATT/WTO, may become less effective as the prevalence of offshoring rises.

Our paper raises many new questions, both theoretical and empirical. Are international prices best thought of as determined through countless bilateral bargains between buyers and sellers, or rather through anonymous market clearing mechanisms? To the extent that it is the former, Do the trade policy stances of governments in practice have systematic impacts on bargaining outcomes and, through this channel, on trade volumes? Which aspects of the evolving architecture of the GATT/WTO might be best understood from the perspective of the theory we develop here as responses to the rise of offshoring in the world economy? And more generally, does the changing nature of international trade indicate the need for fundamental changes in the nature of regional and multilateral institutions that govern the world trading system? These and related questions strike us as especially fertile areas for further research.

\footnotetext{
${ }^{41}$ It is interesting to observe that the novel channel through which ad valorem tariffs alter the bargaining outcome between home producer and foreign supplier - namely, the slope of the bargaining frontier - also suggests that these policy instruments may have a broader class of applicability with regard to their ability to mitigate international hold-up problems than is the case for specific tariffs. For example, if $x$ were reinterpreted as the unverifiable quality of a fixed unit to be traded, so that tariff policy could not then be conditioned on $x$, a specific tariff on trade in $x$ would lose its ability to affect the hold-up problem, but an ad valorem tariff would continue to be useful in this regard.
} 


\section{Appendix A}

\section{A.1. Second-Order Conditions}

In this Appendix we provide a discussion of the second-order conditions of the main tariff setting games developed in the main text.

\section{Second-Best Policy Choices in the Benchmark Model}

It is easily verified that the second order conditions associated with the first-order conditions in (7) are satisfied. Simply note that evaluated at the equilibrium, we have

$$
\begin{aligned}
\frac{\partial^{2} W^{W}}{\partial\left(\tau_{1}^{H}\right)^{2}} & =\frac{\partial D_{1}}{\partial p_{1}^{H}}+y^{\prime \prime}(\hat{x})\left(\frac{\partial \hat{x}}{\partial \tau_{1}^{H}}\right)^{2}<0 \\
\frac{\partial^{2} W^{W}}{\partial\left(\tau_{x}\right)^{2}} & =y^{\prime \prime}(\hat{x})\left(\frac{\partial \hat{x}}{\partial \tau_{x}}\right)^{2}<0 \\
\frac{\partial^{2} W^{W}}{\partial \tau_{x} \partial \tau_{1}^{H}} & =y^{\prime \prime}(\hat{x}) \frac{\partial \hat{x}}{\partial \tau_{1}^{H}} \frac{\partial \hat{x}}{\partial \tau_{x}}>0
\end{aligned}
$$

and thus $\left(\partial^{2} W^{W} / \partial\left(\tau_{1}^{H}\right)^{2}\right)\left(\partial^{2} W^{W} / \partial\left(\tau_{x}\right)^{2}\right)-\left(\partial^{2} W^{W} / \partial \tau_{x} \partial \tau_{1}^{H}\right)^{2}=\left(\partial D_{1} / \partial p_{1}^{H}\right) y^{\prime \prime}(\hat{x})\left(\partial \hat{x} / \partial \tau_{x}\right)^{2}>0$.

\section{Nash Equilibrium Policy Choices in the Benchmark Model}

We now consider the second-order conditions of the Nash equilibrium. Using equation (14), that is $\frac{1}{2}\left(1+\hat{\tau}_{1}^{H}\right) y^{\prime}(\hat{x})=$ $1+\frac{1}{2} \hat{\tau}_{x}^{H}+\frac{1}{2} \hat{\tau}_{x}^{F}$, we can simplify the first-order conditions to obtain:

$$
\begin{aligned}
\frac{\partial W^{H}}{\partial \tau_{1}^{H}} & =0=\tau_{1}^{H} \frac{\partial D_{1}}{\partial p_{1}^{H}}-\frac{1}{2} y(\hat{x})+\left[y^{\prime}(\hat{x})-1-\tau_{x}^{F}\right] \frac{\partial \hat{x}}{\partial \tau_{1}^{H}} \\
\frac{\partial W^{H}}{\partial \tau_{x}^{H}} & =0=\frac{1}{2} \hat{x}+\left[y^{\prime}(\hat{x})-1-\tau_{x}^{F}\right] \frac{\partial \hat{x}}{\partial \tau_{x}^{H}}, \text { and } \\
\frac{\partial W^{F}}{\partial \tau_{x}^{F}} & =0=\frac{1}{2} \hat{x}+\tau_{x}^{F} \frac{\partial \hat{x}}{\partial \tau_{x}^{F}}
\end{aligned}
$$

Consider first the second-order condition for the choice of $\tau_{x}^{F}$, i.e., $\partial^{2} W^{H} / \partial\left(\tau_{x}^{F}\right)^{2}<0$. Differentiating the last expression above with respect to $\tau_{x}^{F}$, we have

$$
\frac{\partial^{2} W^{F}}{\partial\left(\tau_{x}^{F}\right)^{2}}=\frac{3}{2} \frac{\partial \hat{x}}{\partial \tau_{x}^{F}}+\tau_{x}^{F} \frac{\partial^{2} \hat{x}}{\partial\left(\tau_{x}^{F}\right)^{2}} .
$$

But using the implicit function theorem on (14), we have

$$
\frac{\partial \hat{x}}{\partial \tau_{x}^{F}}=\frac{1}{\left(1+\tau_{1}^{H}\right) y^{\prime \prime}(\hat{x})},
$$

which implies

$$
\frac{\partial^{2} \hat{x}}{\partial\left(\tau_{x}^{F}\right)^{2}}=-\frac{1}{\left(1+\tau_{1}^{H}\right)\left(y^{\prime \prime}(\hat{x})\right)^{2}} y^{\prime \prime \prime}(\hat{x}) \frac{\partial \hat{x}}{\partial \tau_{x}^{F}}
$$


Using these expressions as well as $\tau_{x}^{F}=-\frac{1}{2} \hat{x} /\left(\partial \hat{x} / \partial \tau_{x}^{F}\right)$, we can write (A1) as

$$
\frac{\partial^{2} W^{F}}{\partial\left(\tau_{x}^{F}\right)^{2}}=\frac{1}{2} \frac{\partial \hat{x}}{\partial \tau_{x}^{F}}\left(3+\frac{\hat{x} y^{\prime \prime \prime}(\hat{x})}{y^{\prime \prime}(\hat{x})}\right)
$$

which is negative only if $3+\hat{x} y^{\prime \prime \prime}(\hat{x}) / y^{\prime \prime}(\hat{x})>0$. As an example, assume that $y(x)=x^{\eta} / \eta$, with $\eta \in(0,1)$. In such case, we have $y^{\prime \prime}(x)=(\eta-1) x^{\eta-2}$ and $y^{\prime \prime \prime}(x)=(\eta-2)(\eta-1) x^{\eta-3}$, and hence $3+\hat{x} y^{\prime \prime \prime}(\hat{x}) / y^{\prime \prime}(\hat{x})=$ $1+\eta$, which is indeed positive.

The fact that in the Nash equilibrium we have $\hat{\tau}_{1}^{H} \neq 0$ implies that the second-order conditions for the choice of $\tau_{1}^{H}$ and $\tau_{x}^{H}$ are quite cumbersome to characterize, as they will now also involve properties of the demand function. Throughout the paper, we simply assume that they are satisfied without providing the exact conditions needed.

We next, however, develop a particular case of our model where the second order conditions are easy to characterize and simple comparative statics can be obtained. In particular, we make the simplifying assumption that demand for the final-good is perfectly elastic, which implies that $\hat{\tau}_{1}^{H}=0$. Under this assumption note that it is sufficient to check that $\partial^{2} W^{H} / \partial\left(\tau_{x}^{H}\right)^{2}<0$, which requires that

$$
\frac{\partial^{2} W^{H}}{\partial\left(\tau_{x}^{H}\right)^{2}}=\frac{1}{2} \frac{\partial \hat{x}}{\partial \tau_{x}^{H}}+y^{\prime \prime}(\hat{x})\left(\frac{\partial \hat{x}}{\partial \tau_{x}^{H}}\right)^{2}+\left[y^{\prime}(\hat{x})-1-\tau_{x}^{F}\right] \frac{\partial^{2} \hat{x}}{\partial\left(\tau_{x}^{H}\right)^{2}}<0
$$

Imposing $\partial W^{H} / \partial \tau_{x}^{H}=0$ to eliminate $\tau_{x}^{F}$ and plugging equations (A2) and (A3) - which also apply for $\tau_{x}^{H}$ - , we can simplify the above expression to:

$$
\frac{\partial^{2} W^{H}}{\partial\left(\tau_{x}^{H}\right)^{2}}=\frac{1}{2} \frac{\partial \hat{x}}{\partial \tau_{x}^{H}}\left(3+\frac{\hat{x} y^{\prime \prime \prime}(\hat{x})}{y^{\prime \prime}(\hat{x})}\right)<0
$$

This again requires $3+\hat{x} y^{\prime \prime \prime}(\hat{x}) / y^{\prime \prime}(\hat{x})>0$, which is the same condition as in the choice of $\tau_{x}^{F}$.

\section{A.2. Non-Negativity Constraints}

In the extension of the model in section 5.1, we have ignored situations in which equilibrium trade policies might violate the non-negativity constraints on the outside options and the surplus available to agents in the negotiation. The purpose of this Appendix is to explore those situations and show how they do not invalidate the main results of the paper. To save space, we focus on an analysis of the case with symmetric Nash bargaining, and only briefly comment on the model with generalized bargaining. With symmetric bargaining power, the surplus over which the producer and the supplier bargain is given by

$$
\left(1+\tau_{1}^{H}\right) y(\hat{x})-\left(\tau_{x}^{H}+\tau_{x}^{F}\right) \hat{x}
$$

where remember that the equilibrium $\hat{x}$ satisfies

$$
\frac{1}{2}\left(1+\tau_{1}^{H}\right) y^{\prime}(\hat{x})=1+\frac{1}{2} \tau_{x}^{H}+\frac{1}{2} \tau_{x}^{F}
$$

Our first result is that regardless of the equilibrium values of $\tau_{1}^{H}, \tau_{x}^{H}$, and $\tau_{x}^{F}$, the surplus in equation (A4) will always be non-negative. To see this, note that using (A5) we can write

$$
\left(1+\tau_{1}^{H}\right) y(\hat{x}) \geq\left(1+\tau_{1}^{H}\right) \hat{x} y^{\prime}(\hat{x})=2 \hat{x}+\hat{x} \tau_{x}^{H}+\hat{x} \tau_{x}^{F} \geq \hat{x} \tau_{x}^{H}+\hat{x} \tau_{x}^{F},
$$


where we have used that the concavity of $y(\cdot)$ implies $y^{\prime}(\hat{x}) \hat{x}<y(\hat{x})$. Hence, the non-negativity constraint on the surplus can be ignored hereafter. Intuitively, no matter how distortionary trade taxes are, the level of investment $x$ will adjust to ensure a positive joint surplus of the relationship.

Matters are not as simple with regards to the outside option of each producer. In particular, we are now careful to define this outside option as follows:

$$
\max \left\{\frac{1}{2} \delta\left(1+\tau_{1}^{H}\right) y(x)-\frac{1}{2}\left(\tau_{x}^{H}+\tau_{x}^{F}\right) x, 0\right\} .
$$

It is straightforward to see that whenever $\delta \rightarrow 0$, both producers will find it optimal to ignore the secondary market and simply throw away the amount $x$ of input produced. In such a case, both outside options are zero and the (ex-post) payoff to both the producer and the supplier is given by

$$
\pi^{F}=\pi^{S}=\frac{1}{2}\left(\left(1+\tau_{1}^{H}\right) y(x)-\left(\tau_{x}^{H}+\tau_{x}^{F}\right) x\right),
$$

which is the same expression as in the Benchmark model and as in the model in section 5.1 when $\alpha=1 / 2$. This implies that the analysis remains unchanged even when the non-negativity constraint is taken into account.

Finally, consider the model in section 5.1 with general bargaining power $\alpha$ for Home producers. In such a case, it will also be true that for a low enough $\delta$, the outside option of either home producers or foreign suppliers will be non-negative, in which case the secondary market will remain inactive. As a result, generalized Nash bargaining in stage 3 will leave the final-good producer in $H$ with a payoff equal to $\alpha\left(1+\tau_{1}^{H}\right) y(x)-\alpha\left(\tau_{x}^{H}+\tau_{x}^{F}\right) x$, with the supplier in $F$ now receiving a stage-3 payoff of $(1-\alpha)(1+$ $\left.\tau_{1}^{H}\right) y(x)-(1-\alpha)\left(\tau_{x}^{H}+\tau_{x}^{F}\right) x$. These are the same expressions we obtained in section 5.1 , and hence the same results will apply.

\section{A.3. Location of the Secondary Market}

We consider here the possibility that the secondary market for the foreign supplier is located in the foreign country. This implies that, in the event of disagreement with the final-good producer in $H$, the input supplier in $F$ sells the inputs locally in the foreign country rather than exporting to an alternative buyer in $H$. There are a number of reasons to think that this possibility could be reflected in a richer model (e.g., as a result of search frictions associated with finding international partners on short notice that can be avoided with domestic matches), but rather than attempting to model these reasons explicitly we simply assume outright that there exists a secondary market in the foreign country (only) where a match with a local producer results in the production of an amount $y(x)$ of the generic good, and we return to the assumption of symmetric bargaining power.

The key difference relative to the Benchmark Model is in the outside options. The home producers now obtain no income in the secondary market, while foreign producers now obtain $\frac{1}{2} \delta\left(1+\tau_{1}^{F}\right) y(x)$ in that market, where $\tau_{1}^{F}$ is a foreign trade tax on the final good. Arguing as before, it is easy to see that the final-good producer in $H$ now has a stage-3 payoff of

$$
\frac{1}{2}\left[\left(1+\tau_{1}^{H}\right)-\frac{1}{2} \delta\left(1+\tau_{1}^{F}\right)\right] y(x)-\frac{1}{2}\left(\tau_{x}^{H}+\tau_{x}^{F}\right) x,
$$


with the supplier in $F$ now receiving a stage-3 payoff of

$$
\frac{1}{2}\left[\left(1+\tau_{1}^{H}\right)+\frac{1}{2} \delta\left(1+\tau_{1}^{F}\right)\right] y(x)-\frac{1}{2}\left(\tau_{x}^{H}+\tau_{x}^{F}\right) x,
$$

so that the stage- 2 choice of $\hat{x}$ is now defined by

$$
\frac{1}{2}\left[\left(1+\tau_{1}^{H}\right)+\frac{1}{2} \delta\left(1+\tau_{1}^{F}\right)\right] y^{\prime}(\hat{x})=1+\frac{1}{2}\left(\tau_{x}^{H}+\tau_{x}^{F}\right),
$$

and hence the stage-1 payoffs of the home and foreign firm are given by

$$
\begin{aligned}
\pi^{H} & =\frac{1}{2}\left[\left(1+\tau_{1}^{H}\right)-\frac{1}{2} \delta\left(1+\tau_{1}^{F}\right)\right] y(\hat{x})-\frac{1}{2}\left(\tau_{x}^{H}+\tau_{x}^{F}\right) \hat{x}, \text { and } \\
\pi^{F} & =\frac{1}{2}\left[\left(1+\tau_{1}^{H}\right)+\frac{1}{2} \delta\left(1+\tau_{1}^{F}\right)\right] y(\hat{x})-\frac{1}{2}\left(\tau_{x}^{H}+\tau_{x}^{F}\right) \hat{x}-\hat{x} .
\end{aligned}
$$

Anticipating that $F$ may now have reason to alter $p_{1}^{F}$ with its choice of $\tau_{1}^{F}$ (for reasons analogous to $H$ 's incentive to alter $p_{1}^{H}$ with its choice of $\tau_{1}^{H}$ ) and hence affect foreign consumer surplus $C S\left(p_{1}^{F}\right)$, and noting that none (or to be precise, a measure 0 ) of good 1 is actually produced in $F$ in equilibrium, home and foreign welfare are then given by

$$
\begin{aligned}
W^{H} & =C S\left(p_{1}^{H}\right)+\pi^{H}+\tau_{1}^{H}\left[D_{1}\left(p_{1}^{H}\right)-y(\hat{x})\right]+\tau_{x}^{H} \hat{x}, \text { and } \\
W^{F} & =C S\left(p_{1}^{F}\right)+\pi^{F}+\tau_{1}^{F} D\left(p_{1}^{F}\right)+\tau_{x}^{F} \hat{x} .
\end{aligned}
$$

The first-order conditions that define the Nash policies $\hat{\tau}_{1}^{H N}, \hat{\tau}_{x}^{H N}, \hat{\tau}_{1}^{F N}$ and $\hat{\tau}_{x}^{F N}$ can be manipulated to yield

$$
\begin{aligned}
\hat{\tau}_{1}^{H N} & =\frac{\frac{1}{2} \hat{x}\left[y^{\prime}(\hat{x})-\frac{y(\hat{x})}{\hat{x}}\right]}{-\partial D_{1} / \partial p_{1}^{H}}, \\
\hat{\tau}_{x}^{H N} & =-\left[\left(1-\tau_{1}^{H}\right)-\frac{1}{2} \delta\left(1+\tau_{1}^{F}\right)\right] y^{\prime}(\hat{x})-\frac{\hat{x}}{\partial \hat{x} / \partial \tau_{x}^{H}}+\hat{\tau}_{x}^{F N}, \\
\hat{\tau}_{1}^{F N} & =\frac{\frac{1}{4} \delta \hat{x}\left[y^{\prime}(\hat{x})+\frac{y(\hat{x})}{\hat{x}}\right]}{-\partial D_{1} / \partial p_{1}^{F}}, \text { and } \\
\hat{\tau}_{x}^{F N} & =-\frac{1}{2} \frac{\hat{x}}{\partial \hat{x} / \partial \tau_{x}^{F}} .
\end{aligned}
$$

Again, the expression for $\hat{\tau}_{1}^{H N}$ is negative, and is similar to the expression derived in the Benchmark Model and contained in (10). The intuition is also analogous to that in the Benchmark Model: the home government finds it optimal to set a negative $\hat{\tau}_{1}^{H N}$ as a means of shifting surplus from foreign suppliers to the home country. The dual role that $\hat{\tau}_{x}^{H N}$ plays in alleviating the hold-up problem and at same time transferring surplus implies again that its sign is in general ambiguous.

This extension of the model delivers more interesting implications for the Nash policies adopted by the foreign government. First, as in the Benchmark model, the foreign government has an incentive to set a positive export tax on the intermediate input $\left(\hat{\tau}_{x}^{F N}>0\right)$, because the foreign input supplier can pass part of this cost on to home producers by threatening not to deliver the intermediate input. The key for this is that the outside option for the supplier is not reduced one to one with $\tau_{x}^{F}$. In the present variant of the model, this is not only due to less-than-full bargaining power for suppliers but also to the fact that the secondary 
market does not involve trade flows.

Second, and contrary to all of the models explored above, foreign taxes on the final good 1 can now affect the distribution of surplus between home and foreign producers. As a result, the foreign government now chooses to optimally balance the relative roles of $\hat{\tau}_{x}^{F N}$ and $\hat{\tau}_{1}^{F N}$ in extracting surplus from home firms in the same way that the home government balances $\hat{\tau}_{x}^{H N}$ and $\hat{\tau}_{1}^{H N}$ in extracting surplus from foreign firms. For the foreign government this implies the use of a foreign import tariff or export subsidy $\left(\hat{\tau}_{1}^{F N}>0\right)$ on the final good in order to raise $p_{1}^{F}$ and thus improve the outside option (and bargaining position) of foreign suppliers.

Although we have shown that the location of the secondary market has implications for the Nash equilibrium values of home and foreign trade policies, it is important again to emphasize the two general features of our model that continue to hold in this extension as well. First, manipulating the above first-order conditions and applying the implicit function theorem to (A7), we find

$$
y^{\prime}(\hat{x})=1-\frac{\hat{x}}{\partial \hat{x} / \partial \tau_{x}^{H}}>1,
$$

which indicates that again, under Nash policy choices, the international hold-up problem persists and the volume of international input trade is inefficiently low as a consequence. Second, as we have indicated our model predicts the equilibrium use of taxes in the final good market and these distortions arise as a result of each country's attempts to extract bargaining surplus from firms abroad. Once again therefore, the purpose of a trade agreement remains to help governments better solve these two problems.

\section{Appendix B: A Competitive Benchmark}

For comparison, we now develop the competitive analogue of our (political-economy augmented) model. We suppose that foreign inputs are competitively supplied according to the supply curve

$$
x_{S}^{F} \equiv x_{S}^{F}\left(p_{x}^{F}\right),
$$

In country $H$, the final good 1 is produced according to the concave production function $y(x)$, and the marginal cost of production of final good 1 is given by

$$
m c_{1}^{H}=\frac{p_{x}^{H}}{y^{\prime}(x)} .
$$

Competitive supply of final good 1 in country $H$ is then determined according to $p_{1}^{H}=m c_{1}^{H}$ or

$$
p_{1}^{H}=\frac{p_{x}^{H}}{y^{\prime}\left(x_{D}^{H}\right)},
$$

which implicitly defines $x_{D}^{H}$, the derived demand for the input $x$, as

$$
x_{D}^{H}=y^{-1}\left(p_{x}^{H} / p_{1}^{H}\right) \equiv x_{D}^{H}\left(p_{1}^{H}, p_{x}^{H}\right) .
$$

The pricing relationships are (with $p_{x}^{*}$ the international or world/untaxed price):

$$
p_{1}^{H}=1+\tau_{1}^{H} \equiv p_{1}^{H}\left(\tau_{1}^{H}\right) ; \quad p_{x}^{H}=p_{x}^{*}+\tau_{x}^{H} \equiv p_{x}^{H}\left(\tau_{x}^{H}, p_{x}^{*}\right) ; \quad p_{x}^{F}=p_{x}^{*}-\tau_{x}^{F} \equiv p_{x}^{F}\left(\tau_{x}^{F}, p_{x}^{*}\right) .
$$


The market-clearing condition in the world (home and foreign) $x$ market is then given by $x_{D}^{H}=x_{S}^{F}$, or

$$
x_{D}^{H}\left(p_{1}^{H}\left(\tau_{1}^{H}\right), p_{x}^{H}\left(\tau_{x}^{H}, p_{x}^{*}\right)\right)=x_{S}^{F}\left(p_{x}^{F}\left(\tau_{x}^{F}, p_{x}^{*}\right)\right),
$$

which determines $p_{x}^{*}\left(\tau_{1}^{H}, \tau_{x}^{H}, \tau_{x}^{F}\right)$. Market-clearing input trade volume may then be written as $\hat{x}\left(p_{1}^{H}, p_{x}^{H}\right) \equiv$ $x_{D}^{H}\left(p_{1}^{H}\left(\tau_{1}^{H}\right), p_{x}^{H}\left(\tau_{x}^{H}, p_{x}^{*}\left(\tau_{1}^{H}, \tau_{x}^{H}, \tau_{x}^{F}\right)\right)\right)$ or equivalently $\hat{x}\left(p_{x}^{F}\right) \equiv x_{S}^{F}\left(p_{x}^{F}\left(\tau_{x}^{F}, p_{x}^{*}\left(\tau_{1}^{H}, \tau_{x}^{H}, \tau_{x}^{F}\right)\right)\right)$. We also have $y\left(p_{1}^{H}, p_{x}^{H}\right) \equiv y\left(\hat{x}\left(p_{1}^{H}, p_{x}^{H}\right)\right)$. Notice that (B1) can be differentiated to yield

$$
\frac{\partial p_{x}^{*}}{\partial \tau_{x}^{H}}=\frac{-\frac{\partial x_{D}^{H}\left(p_{1}^{H}, p_{x}^{H}\right)}{\partial p_{x}^{H}}}{\frac{\partial x_{D}^{H}\left(p_{1}^{H}, p_{x}^{H}\right)}{\partial p_{x}^{H}}-\frac{\partial x_{S}^{F}\left(p_{x}^{F}\right)}{\partial p_{x}^{F}}}<0 ; \quad \frac{\partial p_{x}^{*}}{\partial \tau_{x}^{F}}=\frac{-\frac{\partial x_{S}^{F}\left(p_{x}^{F}\right)}{\partial p_{x}^{F}}}{\frac{\partial x_{D}^{H}\left(p_{1}^{H}, p_{x}^{H}\right)}{\partial p_{x}^{H}}-\frac{\partial x_{S}^{F}\left(p_{x}^{F}\right)}{\partial p_{x}^{F}}}>0,
$$

and so we have that

$$
1=\frac{\partial p_{x}^{*}}{\partial \tau_{x}^{F}}-\frac{\partial p_{x}^{*}}{\partial \tau_{x}^{H}}
$$

The home welfare function may now be written as:

$$
W^{H}=C S\left(p_{1}^{H}\right)+\gamma^{H} \int_{0}^{p_{1}^{H}} y\left(p, p_{x}^{H}\right) d p+\left(p_{1}^{H}-1\right)\left[D_{1}^{H}\left(p_{1}^{H}\right)-y\left(p_{1}^{H}, p_{x}^{H}\right)\right]+\left(p_{x}^{H}-p_{x}^{*}\right) \hat{x}\left(p_{1}^{H}, p_{x}^{H}\right),
$$

or

$$
W^{H} \equiv W^{H}\left(p_{1}^{H}, p_{x}^{H}, p_{x}^{*}\right)
$$

Similarly, the foreign welfare function may now be written as:

$$
W^{F}=C S(1)+\gamma^{F} \int_{0}^{p_{x}^{F}} x_{S}^{F}(p) d p+\left(p_{x}^{*}-p_{x}^{F}\right) \hat{x}\left(p_{x}^{F}\right)
$$

or

$$
W^{F} \equiv W^{F}\left(p_{x}^{F}, p_{x}^{*}\right)
$$

Using the fact that $W_{p_{x}^{*}}^{F}=-W_{p_{x}^{*}}^{H}=\hat{x}$, the efficiency frontier is defined by the three conditions:

$$
\begin{aligned}
W_{p_{x}^{H}}^{H}+\left[W_{p_{x}^{H}}^{H}+W_{p_{x}^{F}}^{F}\right] \frac{\partial p_{x}^{*}}{\partial \tau_{x}^{H}} & =0, \\
-W_{p_{x}^{F}}^{F}+\left[W_{p_{x}^{F}}^{F}+W_{p_{x}^{H}}^{H}\right] \frac{\partial p_{x}^{*}}{\partial \tau_{x}^{F}} & =0, \text { and } \\
W_{p_{1}^{H}}^{H}+\left[W_{p_{x}^{H}}^{H}+W_{p_{x}^{F}}^{F}\right] \frac{\partial p_{x}^{*}}{\partial \tau_{1}^{H}} & =0 .
\end{aligned}
$$

Using (B2), it is easy to show that the first two first-order conditions are identical, and therefore determine the sum of $\tau_{x}^{H}$ and $\tau_{x}^{F}$ that is consistent with international efficiency.

To further interpret the conditions for efficiency, we multiply the first efficiency condition by $-\left[\frac{\partial p_{x}^{*} / \partial \tau_{1}^{H}}{\partial p_{x}^{*} / \partial \tau_{x}^{H}}\right]$ and add it to the third efficiency condition, so that we may then restate the two conditions for international efficiency as

$$
\begin{aligned}
W_{p_{x}^{H}}^{H}+\left[W_{p_{x}^{H}}^{H}+W_{p_{x}^{F}}^{F}\right] \frac{\partial p_{x}^{*}}{\partial \tau_{x}^{H}} & =0, \text { and } \\
W_{p_{1}^{H}}^{H}-W_{p_{x}^{H}}^{H} \cdot \frac{\partial p_{x}^{*} / \partial \tau_{1}^{H}}{\partial p_{x}^{*} / \partial \tau_{x}^{H}} & =0 .
\end{aligned}
$$


The interpretation of (B3) is as follows. Let us begin with the second efficiency condition. On the lefthand side is the impact on home welfare of (infinitessimal) changes in the mix of $\tau_{1}^{H}$ and $\tau_{x}^{H}$ which hold fixed $p_{x}^{*}$ - and hence, by (B1) and with $\tau_{x}^{F}$ and thus $p_{x}^{F}\left(\tau_{x}^{F}, p_{x}^{*}\right)$ unchanged, hold fixed as well the level of $x_{D}^{H}$ and therefore the equilibrium level of input trade volume $\hat{x}$. Notice, though, that foreign welfare $W^{F}\left(p_{x}^{F}\left(\tau_{x}^{F}, p_{x}^{*}\right), p_{x}^{*}\right)$ is unaffected by such changes, because $p_{x}^{*}$ is held fixed and $\tau_{x}^{F}$ is not changed and so, as already mentioned, $p_{x}^{F}\left(\tau_{x}^{F}, p_{x}^{*}\right)$ is held fixed as well. Hence, the second efficiency condition in (B3) says simply that, at internationally efficient choices of $\tau_{1}^{H}$ and $\tau_{x}^{H}$, such changes can have no first-order effect on home welfare either. The first efficiency condition in (B3) then ensures that the sum of $\tau_{x}^{H}$ and $\tau_{x}^{F}$ achieves the efficient level of $p_{x}^{F}$, and hence the efficient level of input trade volume in light of the mix of $\tau_{1}^{H}$ and $\tau_{x}^{H}$ that the home country employs to deliver the chosen level of $p_{x}^{*}$ and (with $\tau_{x}^{F}$ fixed) $p_{x}^{F}$.

Next consider the Nash policies. The associated first-order conditions are

$$
\begin{aligned}
W_{p_{x}^{H}}^{H}+\left[W_{p_{x}^{H}}^{H}+W_{p_{x}^{*}}^{H}\right] \frac{\partial p_{x}^{*}}{\partial \tau_{x}^{H}} & =0, \\
-W_{p_{x}^{F}}^{F}+\left[W_{p_{x}^{F}}^{F}+W_{p_{x}^{*}}^{F}\right] \frac{\partial p_{x}^{*}}{\partial \tau_{x}^{F}} & =0, \text { and } \\
W_{p_{1}^{H}}^{H}+\left[W_{p_{x}^{H}}^{H}+W_{p_{x}^{*}}^{H}\right] \frac{\partial p_{x}^{*}}{\partial \tau_{1}^{H}} & =0 .
\end{aligned}
$$

Using (B2) and $W_{p_{x}^{*}}^{F}=-W_{p_{x}^{*}}^{H}$, the first two Nash first-order conditions can be added together to yield:

$$
W_{p_{x}^{H}}^{H}+\left[W_{p_{x}^{H}}^{H}+W_{p_{x}^{F}}^{F}\right] \frac{\partial p_{x}^{*}}{\partial \tau_{x}^{H}}+W_{p_{x}^{*}}^{F}=0 .
$$

Comparing (B5) to the first efficiency condition in (B3), the difference is the additional term $W_{p_{x}^{*}}^{F}>0$ on the left-hand side of (B5), which implies that the sum $\tau_{x}^{H}+\tau_{x}^{F}$ is inefficiently high (the first-order condition for efficiency is negative at the Nash taxes), and therefore that the Nash level of input trade volume is inefficiently low in light of the mix of $\tau_{1}^{H}$ and $\tau_{x}^{H}$ that the home country employs in the Nash equilibrium to deliver the chosen level of $p_{x}^{*}$ and (with $\tau_{x}^{F}$ fixed) $p_{x}^{F}$.

Next we multiply the initial first-order condition in (B4) by $-\left[\frac{\partial p_{x}^{*} / \partial \tau_{1}^{H}}{\partial p_{x}^{*} / \partial \tau_{x}^{H}}\right]$ and add it to the last first-order condition to get

$$
W_{p_{1}^{H}}^{H}-W_{p_{x}^{H}}^{H} \cdot \frac{\partial p_{x}^{*} / \partial \tau_{1}^{H}}{\partial p_{x}^{*} / \partial \tau_{x}^{H}}=0
$$

Comparing (B6) to the second efficiency condition in (B3), we may conclude that the mix of $\tau_{1}^{H}$ and $\tau_{x}^{H}$ that the home country employs in the Nash equilibrium to deliver its chosen level of $p_{x}^{*}$ and hence $p_{x}^{F}-$ and therefore by (B1), $x_{D}^{H}$ and hence $\hat{x}$ - is internationally efficient (see Bagwell and Staiger, 2001, for an analogous observation).

Therefore, we may conclude that the single inefficiency in the Nash equilibrium in our competitive benchmark model is that the sum $\tau_{x}^{H}+\tau_{x}^{F}$ is inefficiently high, and hence that there is too little equilibrium input trade volume/input "market access": in the competitive benchmark model, the task of a trade agreement is thus to expand and secure market access to internationally efficient levels (see Bagwell and Staiger, 2001, 2002, for an interpretation of analogous findings from a market access perspective).

Next consider the political optimum conditions. Specifically, consider the hypothetical situation that governments are not motivated by the impact of their tariff choices on $p_{x}^{*}$, in the specific sense that $W_{p_{x}^{*}}^{H} \frac{\partial p_{x}^{*}}{\partial \tau_{1}^{H}}=$ $W_{p_{x}^{*}}^{H} \frac{\partial p_{x}^{*}}{\partial \tau_{x}^{H}} \equiv 0$ and similarly for $W^{F}$. We then identify the tariffs that would be chosen unilaterally (i.e., non- 
cooperatively) by governments with these hypothetical preferences and ask whether these tariffs are efficient with respect to the actual government preferences. This is Bagwell and Staiger's (1999) original definition, and it is direct to show using (B4) that in our competitive benchmark model the following conditions define the political optimum:

$$
W_{p_{x}^{H}}^{H}=0, W_{p_{x}^{F}}^{F}=0, \text { and } W_{p_{1}^{H}}^{H}=0 .
$$

Clearly, as an examination of (B3) indicates, the political optimum defined in (B7) is efficient in this setting, whether or not governments are motivated by political economy concerns, so we now have shown that the standard terms-of-trade theory applies in a competitive-supplier version of our set-up. 


\section{References}

Aghion, Philippe, Pol Antràs, and Elhanan Helpman (2007), "Negotiating Free Trade," Journal of International Economics, Vol. 73, No. 1, pp. 1-30.

Antràs, Pol. (2003), "Firms, Contracts, and Trade Structure," Quarterly Journal of Economics, 118:4, pp. $1375-1418$.

Antràs, Pol (2005), "Incomplete Contracts and the Product Cycle," American Economic Review, 95:4, pp. 1054-1073.

Antràs, Pol, Luis Garicano and Esteban Rossi-Hansberg (2006), "Offshoring in a Knowledge Economy," Quarterly Journal of Economics, 121:1, pp. 31-77.

Antràs, Pol, and Elhanan Helpman (2004), "Global Sourcing," Journal of Political Economy 112:3, pp. $552-580$.

Antràs, Pol and Esteban Rossi-Hansberg (2008), "Organizations and Trade," Annual Review of Economics, forthcoming.

Bagwell, Kyle and Robert W. Staiger (1999), "An Economic Theory of GATT," American Economic Review, Vol. 89, No. 1, pp. 215-248.

Bagwell, Kyle and Robert W. Staiger (2001), "Domestic Policies, National Sovereignty and International Economic Institutions," Quarterly Journal of Economics, Vol. 116, No. 2, pp. 519-562.

Bagwell, Kyle and Robert W. Staiger (2002), The Economics of the World Trading System, MIT Press.

Bagwell, Kyle and Robert W. Staiger (2006), "What Do Trade Negotiators Negotiate About? Empirical Evidence from the World Trade Organization," NBER Working Paper No. 12727.

Baron, David (1994), "Electoral Competition with Informed and Uninformed Voters," American Political Science Review, 88(1), pp. 33-47.

Bhagwati, Jagdish and V. K. Ramaswami (1963), "Domestic Distortions, Tariffs, and the Theory of Optimum Subsidy," Journal of Political Economy, 71:1, pp., 44-50.

Blanchard, Emily (2006), "Foreign Direct Investment, Endogenous Tariffs, and Preferential Trade Agreements," working paper University of Virginia.

Bolton, Patrick and Mathias Dewatripont (2005), Contract Theory, MIT Press.

Borga, Maria and William J. Zeile (2004), "International Fragmentation of Production and Intrafirm Trade of U.S. Multinational Companies," Bureau of Economic Analysis Working Paper WP \# 2004-02.

Brander, James A. and Barbara J. Spencer (1985), "Export Subsidies and International Market Share Rivalry," Journal of International Economics, 18:1-2, pp. 83-100.

Campa, Jose M., and Goldberg, Linda S. (1997), "The Evolving External Orientation of Manufacturing Industries: Evidence from Four Countries." Federal Reserve Bank of New York Economic Policy Review, 3 (July), pp. 53-81.

Coase, Ronald H. (1937), "The Nature of the Firm," Economica, 4:16, pp. 386-405.

Deardorff, Alan V. (2001), "Fragmentation in Simple Trade Models," North American Journal of International Economics and Finance, 12(2), p. 121-137. 
Diez, Federico J. (2008), "The Disparate Effects of Tariffs on Offshoring Industries," Mimeo, University of Wisconsin, August.

Economist, The. "The Ins and Outs of Outing." (August 31, 1991): 54-56.

Ethier, Wilfred J. (2004), "Political Externalities, Nondiscrimination, and a Multilateral World," Review of International Economics, Vol. 12, No. 3, pp. 303-320.

Feenstra, Robert C. (1998), "Integration of Trade and Disintegration of Production in the Global Economy." Journal of Economic Perspectives 12 (Autumn), pp. 31-50.

Feenstra, Robert C., and Gordon H. Hanson (1996a), "Foreign Investment, Outsourcing and Relative Wages," in Robert C. Feenstra, Gene M. Grossman, and Douglas A. Irwin, eds., Political Economy of Trade Policy: Essays in Honor of Jagdish Bhagwati (Cambridge. MA: MIT Press), pp. 89-127.

Feenstra, Robert C., and Hanson, Gordon H. (1996b), "Globalization, Outsourcing, and Wage Inequality." American Economic Review, 86:2, pp. 240-245.

Feenstra, Robert C., and Hanson, Gordon H. (2005), "Ownership and Control in Outsourcing to China: Estimating the Property Rights Theory of the Firm," Quarterly Journal of Economics, 120(2): 729762.

Grossman, Gene M. and Elhanan Helpman (1994), "Protection for Sale," American Economic Review, Vol. 84, No. 4, pp. 833-850.

Grossman, Gene M. and Elhanan Helpman (1996), "Electoral Competition and Special Interest Politics," Review of Economic Studies, 63:2, pp. 265-286

Grossman, Gene M. and Elhanan Helpman (2002), "Integration vs. Outsourcing in Industry Equilibrium," Quarterly Journal of Economics 117 (1), 85-120.

Grossman, Gene M. and Elhanan Helpman (2005), "Outsourcing in a Global Economy," Review of Economic Studies, 72:1, pp. 135-159.

Grossman, Gene M. and Esteban Rossi-Hansberg (2008), "Trading Tasks: A Simple Theory of Offshoring," forthcoming American Economic Review.

Grossman, Sanford J., and Oliver D. Hart (1986), "The Costs and Benefits of Ownership: A Theory of Vertical and Lateral Integration," Journal of Political Economy, 94:4, pp. 691-719.

Hart, Oliver and John Moore (1990), "Property Rights and the Nature of the Firm," Journal of Political Economy, 98:6, pp. 1119-1158.

Helpman, Elhanan (2006), "Trade, FDI and the Organization of Firms," Journal of Economic Literature, 44, pp.589-630.

Hummels, David; Ishii, Jun; and Yi, Kei-Mu. (2001), "The Nature and Growth of Vertical Specialization in World Trade." Journal of International Economics, 54, pp. 75-96.

Johnson, Harry G. (1965), "Optimal Intervention in the Presence of Domestic Distortions," in R. E. Caves, P. B. Kenen, and H.G. Johnson, eds., Trade, Growth and the Balance of Payments: Essays in Honor of Gottfried Haberler, Amsterdam: North-Holland, pp. 3-34.

Jones, Ronald W. (2000), Globalization and the Theory of Input Trade, Cambridge: MIT Press. 
Levchenko, Andrei (2007), "Institutional Quality and International Trade," Review of Economic Studies, $74: 3,791-819$.

McLaren, John (1997), "Size, Sunk Costs, and Judge Bowker's Objection to Free Trade," American Economic Review, Vol. 87, No. 3, pp. 400-420.

McLaren, John (2000), "Globalization and Vertical Structure," American Economic Review, 90, pp. 12391254.

Nunn, Nathan (2007), "Relationship-Specificity, Incomplete Contracts and the Pattern of Trade," Quarterly Journal of Economics, Vol. 122, No. 2, pp. 569-600.

Nunn, Nathan and Dan Trefler (2008), "The Boundaries of the Multinational Firm: An Empirical Analysis." In Globalization and the Organization of Firms and Markets, edited by Elhanan Helpman and Dalia Marin. Cambridge, MA: Harvard University Press, forthcoming.

Ornelas, Emanuel (2008), "Feasible Multilateralism and the Effects of Regionalism," Journal of International Economics., 74:1, pp. 202-224.

Ornelas, Emanuel and John L. Turner (2008a), "Trade Liberalization, Outsourcing, and the Hold Up Problem," Journal of International Economics, 74:1, pp. 225-241.

Ornelas, Emanuel and John L. Turner (2008b), "Protection and International Sourcing," Mimeo, July 1.

Ossa, Ralph (2008), “A 'New Trade’ Theory of GATT/WTO Negotiations,” Mimeo, May.

Ramanarayanan, Ananth (2006), "International Trade Dynamics with Intermediate Inputs," mimeo University of Minnesota.

Rosenkranz, Stephanie and Patrick W. Schmitz (2007), "Can Coasean bargaining justify Pigouvian taxation?" Economica, vol. 74 (296), pp. 573-585.

Williamson, Oliver E. (1985), The Economic Institutions of Capitalism, Free Press: New York.

Yarbrough, Beth V. and Robert M. Yarbrough (1992), Cooperation and Governance in International Trade: The Strategic Organizational Approach, Princeton University Press.

Yeaple, Stephen R. (2006), "Offshoring, Foreign Direct Investment, and the Structure of U.S. International Trade," Journal of the European Economic Association Papers and Proceedings, 4, pp. 602-611

Yeats, Alexander J. (2001), "Just How Big Is Global Production Sharing?" In Arndt, Sven W., and Kierzkowski, Henry eds., Fragmentation: New Production Patterns in the World Economy, Oxford University Press. 